\title{
Distribuição intra-urbana da temperatura do ar/conforto térmico e condições de vida no Aglomerado Urbano da Região Metropolitana de Curitiba (AU-RMC), Brasil
}

\section{Intra-urban air temperature distribution/thermal comfort and living conditions at the Urban Agglomerate of the Metropolitan Region of Curitiba (AU-RMC), Brazil}

\author{
Eliane Müller Seraphim Dumke'; Francisco de Assis Mendonça ${ }^{2}$
}

\begin{abstract}
Resumo
Curitiba se destaca pelo planejamento urbano. Porém, devido ao acelerado crescimento urbano nas últimas décadas, a cidade se desenvolveu vertical e arealmente envolvendo os municípios vizinhos, formando o Aglomerado Urbano da Região Metropolitana de Curitiba (AU-RMC). O clima urbano revela significativa variabilidade na área urbanizada e resulta em diferentes graus de conforto térmico. Curitiba apresenta desconforto térmico por frio durante o ano e com mais intensidade no inverno, acarretando problemas para a população. A pesquisa se fundamenta nas propostas teórico-metodológicas que verificam as relações sociedade/natureza, espaço/tempo (clima) e a interação global/ local. A partir da cartografia dos elementos do sítio, do fato urbano e de sua correlação, elaborou-se a setorização espacial da cidade, que orientou a geração da rede de monitoramento em campo. A análise temporal resultou na caracterização do clima local sob os aspectos dinâmicos da atmosfera e contextualizou o experimento, indicando os dias representativos de inverno. A Termografia de Superfície, mediante imagem de satélite Landsat 5, possibilitou uma averiguação detalhada da variabilidade do clima intraurbano quanto a temperatura da superfície e sua influencia na temperatura do ar. Os dados climáticos foram coletados in situ em 16 locais selecionados, em 21 agosto de 2006. Confrontando os graus de desconforto térmico com a classificação das condições de vida/qualidade de vida nos locais amostrados, verificou-se a coincidência entre o desconforto pelo frio e por amplitudes térmicas diárias, especialmente onde a pobreza se estabeleceu, devido a configuração socioespacial urbana. Agravam-se assim, os baixos índices de qualidade de vida e a vulnerabilidade socioambiental frente ao clima urbano no período de inverno.
\end{abstract}

Palavras-chave: clima urbano, conforto térmico, condições de vida, Aglomerado Urbano da Região Metropolitana de Curitiba.

\begin{abstract}
Curitiba is recognized for its urban planning. However, due to rapid urban growth in the last decades, the city developed both vertical and horizontally, exceeding its limits towards neighboring cities forming the Urban Agglomerate of the Metropolitan Region of Curitiba (AU-RMC). Curitiba, the coldest capital of Brazil, presents thermal discomfort due to cold temperatures during most of the year, mainly in the winter, what causes problems for its population. It's urban climate exhibits considerable variability; city areas alternate between cool and heat islands, which results in different thermal comfort/discomfort levels. This research is based on the theoretical-methodological and verifies the relations between society/nature, space/time (climate) and global/local interaction. From the cartography of the area, the urban facts and their correlation, a spatial sectorization of the city was elaborated, which guided the generation of the monitoring network in the field. In parallel, the temporal analysis resulted in the characterization of the local climate under the dynamic aspects of the atmosphere and in the experiment's contextualization. A representative winter day was chosen (August, 21st. 2006). Surface Thermography, obtained by Landsat 5 satellite image, allowed a detailed investigation of the intra-urban climate regarding surface temperature and its influence on air temperature. Climatic data was collected in situ in 16 selected sites. Confronting the thermal discomfort degrees with life conditions and life quality at the sampled sites, a coincidence of a double discomfort was verified: by cold and by larger thermal amplitudes, specially where poverty was established, due to urban socio-spatial configuration. This aggravates low life quality indexes and socio-environmental vulnerability due to urban climate in winter.
\end{abstract}

Key words: urban climate, urban heat islands, thermal comfort, urban planning, Aglomerado Urbano da Região Metropolitana de Curitiba.

Recibido el 03 de octubre de 2016, aceptado el 15 de mayo de 2017.

1 Universidade Federal do Paraná (UFPR). Programa de Pós-Graduação em Geografia. Departamento de Geografia. Laboclima. Av. Francisco H dos Santos, s/n. Centro Politécnico. Jardim das Américas. Edifício João José Bigarella, sl. 209.81531-970. Curitiba. PR, Brasil. Email: eliane.dumke@gmail.com

2 Departamento de Geografia. LABOCLIMA-UFPR, Pesquisador 1A/CNPq 


\section{Introdução}

Curitiba, capital do estado do Paraná, situase na região sul do Brasil $\left(25^{\circ} 25^{\prime} 40^{\prime \prime} \mathrm{S}\right.$, $49^{\circ} 16^{\prime} 23^{\prime} \mathrm{W}$ e $934 \mathrm{~m}$ de altitude), em área de clima tropical de altitude ( $\mathrm{Cfb} /$ Koeppen) e dominada por massas de ar tropicais e extratropicais. Considerada a capital mais fría do país, Curitiba é considerada úmida e fria, apresenta grande amplitude térmica diária e anual e tempo frequentemente instável. As temperaturas médias no verão se aproximam dos $20^{\circ} \mathrm{C}$. No inverno as temperaturas são bastante baixas para os padrões tropicais: as temperaturas médias são de $13^{\circ} \mathrm{C}$ em junho e julho. A mínima absoluta chegou a $-5,2^{\circ} \mathrm{C}$, em junho de 1972 (Mendonça \& Danni-Oliveira, 2007).

Porém, o clima urbano resulta da interação das situações sinóticas com as características físicas do sítio e do construto urbano, a vegetação e o calor antropogênico, diferenciando as condições climáticas intraurbanas. Mediante supressão da vegetação nativa, impermeabilização do solo, adensamento populacional, emissão de poluentes, entre outros, a urbanização altera o ambiente natural e a qualidade de vida e tem como um dos seus maiores impactos: a formação de um clima urbano.

No Brasil a urbanização recente se associa à industrialização tardia que ocorreu nos países latinoamericanos em geral. Ao longo do século $\mathrm{XX}$, a urbanização modificou $\mathrm{o}$ Brasil. O crescimento urbano acelerado e desordenado, no processo denominado por Santos (1994) de urbanização corporativa, gerou grandes cidades com inúmeros problemas socioambientais.

Entre os anos 1940 e 1980, se inverteu a localização da residência da população, que deixou de ser rural para ser urbana: a taxa de urbanização no Brasil passou, respectivamente, de $26,35 \%$ para $68,86 \%$, alcançando 81\% em 2000 (IBGE, 2016).

A partir da década de 1940, alterou-se a base econômica das capitais estaduais. A industrialização, os esforçosparaaintegração do território por meio dos transportes e da comunicação, além da expansão do consumo, intensificaram a urbanização. $\mathrm{Na}$ década de 1960, o governo promoveu a incorporação do país ao movimento de globalizalização da economia, atraindo empresas multinacionais. A modernização e o desenvolvimento da economia, o aumento populacional, a expansão da classe media e o acesso ao crédito pelos pobres, levaram ao aumento do consumo e da expansão industrial. Na década de 1970, a urbanização sofreu nova aceleração atingindo um novo padrão com tendência à metropolização (Santos, 1994).

Curitiba também seguiu essa tendência de urbanização. O pequeno povoado de Curitiba fundado em 1693 transformouse, em pouco mais de três séculos, num grande aglomerado urbano. Mas enquanto no Brasil, a maior parte das cidades cresceu de forma desordenada, Curitiba, contou com um processo permanente e institucionalizado de planejamento urbano, desde a década de 1940. Curitiba é conhecida internacionalmente como cidade exemplar. Entretanto, a imagem positiva veiculada sobre Curitiba pelo eficiente citymarketing, se contrapõe aos seus problemas socioambientais.

Em função do crescimento acelerado da cidade, a população triplicou em quatro décadas (1970-2010), sucederam-se os Planos Urbanísticos e suas adaptações, que muitas vezes negligenciaram os critérios bioclimáticos. Assim, a interação entre o clima local, os fatores físico-territoriais e os critérios urbanísticos adotados, criaram uma configuração de espaços urbanos de qualidade climática diferenciada.

$\mathrm{O}$ crescimento de Curitiba se deu tanto vertical como arealmente, extrapolando os limites municipais e envolvendo cidades vizinhas. A formação dessa mancha de ocupação de alta densidade demográfica e sua intensa relação funcional constituiu o aglomerado urbano, com uma população de cerca de 3,2 milhões de habitantes dos quais cerca de 1,8 milhão se concentram no município-pólo, Curitiba.

As propriedades térmicas dos materiais e a estrutura urbana são as causas principais da ilha de calor urbano, Urban Heat Islands 
(UHIs), seguidas por fatores secundários: as fontes de calor antropogênico, poluição do ar e redução da evaporação. Porém, Curitiba não corresponde a uma única ilha de calor urbano sobre o centro da cidade, caracterizado pela concentração de altos edifícios comerciais, Central Business District (CBD), como outrora. Pela sua complexidade, as grandes cidades de hoje comportam a análise de distintas formas urbanas e sua capacidade de impactar o clima local.

Oke (2006), em suas diretrizes para observações meteorológicas representativas em locais urbanos, propõe uma classificação simplificada para estudos de clima urbano/ ilhas de calor. As distintas paisagens são organizadas aproximadamente em ordem decrescente de densidade urbana ou de seu provavel impacto sobre o clima local. $\mathrm{Na}$ classificação em zonas climáticas urbanas (Urban Climate Zone's, UCZ), Oke (2006) estabeleceu para cada UCZ os valores de rugosidade, visão do céu e taxa de impermeabilidade que afetam o clima de forma diferenciada, considerando o uso do solo.

Essa classificação é detalhada em Stewart, Oke \& Krayenhoff (2014). A divisão conceitual de UCZ's é então estabelecida por observações de temperatura e resultados de modelos de simulação superfície-atmosfera. Os 17 padrões encontrados foram definidos por suas propiedades estruturais e de uso do solo que influenciam a temperatura do ar na altura do observador $(1,50 \mathrm{~m})$. $\mathrm{O}$ estudo confirmou diferenças térmicas existentes nas classes de UCZ's, principalmente decorrentes da relação altura e espaçamento das construções, área permeável, densidade de vegetação arbórea e umidade do solo.

O Aglomerado Urbano da Região Metropolitana de Curitiba (AU-RMC) se caracteriza por suas dimensões e a heterogeneidade. Fruto da urbanização acelerada, a mancha urbana se orienta por eixos no município-pólo e se extende formando uma grande cidade polinucleada entremeada de áreas verdes, mesclando diferentes graus de densidade urbana. Essa configuração urbana sugere a descrição de Eliasson (2000), para quem as cidades muitas vezes compreendem um mosaico de áreas com temperaturas mais elevadas e mais baixas conforme a variação do uso do solo, com temperaturas na mancha urbana frequentemente mais altas do que o entorno.

Os estudos de climatologia urbana no Brasil se desenvolveram a partir da década de 1970, quando o geógrafo brasileiro Monteiro (1976) desenvolveu uma importante proposta metodológica sistêmica, holística e interdisciplinar para a elaboração de diagnósticos climáticos, com ênfase na proposição de estratégias para a solução dos problemas ambientais urbanos, o Sistema Clima Urbano (SCU). Desde então, essa proposta orientou a maioria dos estudos de climatologia no Brasil (Lima, Pinheiro, \& Mendonça, 2012). O livro Clima Urbano de Monteiro \& Mendonça (2003), referência para as pesquisas da área no Brasil, discute a abordagem SCU e apresenta os estudos sobre o tema.

Os estudos sobre o clima urbano de Curitiba iniciaram, em geral, na década de 1990, tendo como pioneira Danni-Oliveira (1999) que observou diferenças de temperatura do ar em função da morfologia urbana e dos níveis de tráfego. Danni-Oliveira \& Mendonça (2000) encontraram relações entre a magnitude da ilha de calor urbano e padrões atmosféricos. Seguiram-se, entre outros, os estudos de Rossi \& Krüger (2005) e Pertschi, Lima \& Danni-Oliveira (2010), que investigaram o efeito dos atributos urbanos sobre o clima intraurbano, tais como: o uso e a ocupação do solo, a vegetação, a densidade urbana, a morfologia urbana e o desenho urbano.

Mendonça \& Dubreuil (2005) utilizaram sensoriamento remoto por meio de imagens de satélite Landsat comparandoas com dados meteorológicos. O método possibilitou a análise do clima urbano como como um todo. Os autores concluíram que o campo térmico da área urbana forma arquipélagos de ilhas de calor e de ilhas de frescor, embora se apresente como uma mancha mais quente e homogênea do que a área rural circunvizinha. As paisagens intraurbanas evidenciaram uma 
diferenciação de temperaturas de amplitude térmica de $8^{\circ}$ Celsius correspondentes aos diversos tipos de usos do solo e padrões de urbanização, da industrialização, da densidade da cobertura vegetal e da topografia.

Young \& Rocha (2006), também utilizando imagens Landsat, investigaram a influência das áreas verdes e sua relação com as mudanças térmicas ao longo do tempo. A partir da análise de grandes áreas vegetadas em datas distintas entre 1986 e 2002 e da observação das alterações de uso do solo, da densidade urbana e das condições climáticas, os autores verificaram as possibilidades de alteração do microclima por meio de estratégias de projeto da paisagem (dimensões e distribuição da vegetação).

Krüger \& Dumke (2006), utilizaram dados climáticos coletados em duas estações meteorológicas oficiais, uma dentro da malha urbana e outra na área periurbana. Mediante o tratamento estatístico dos dados e analisando as premissas de Arnfield (2003), verificaram a existência de ilha de calor no AU-RMC.

Entre as pesquisas realizadas sobre o clima urbano no AU-RMC na última década, citam-se:

Rossi, Dumke \& Krüger (2009), atualizaram o ano climático de referência para Curitiba. A primeira avaliação bioclimáticas para Curitiba foi realizada anteriormente por Lamberts, Dutra, \& Pereira (1997), a partir dos, dados horários do TRY (Test Reference Year) para a dédada 1961-1970 e dos parâmetros de Givoni (1992), revelou que $73,2 \%$ das horas anuais em Curitiba eram de desconforto por frio.

Por sua vez, Rossi et al. (2009), ao atualizar o TRY para a década 1998-2007 e comparar as médias das temperaturas mensais entre os TRY respectivamente encontrados (nas avaliações de 1969 e de 2007), constataram o aumento médio de temperatura de $1,9^{\circ} \mathrm{C}$, significativo para um período de 32 anos. Comparando os graus de conforto/ desconforto a partir da análise dos diagramas de conforto de Givoni (1992), verificou-se que a porcentagem de conforto (entre $18^{\circ} \mathrm{C}$ e $29^{\circ} \mathrm{C}$ ) em 2007 aumentou $20 \%$ em relação a 1969 , com o aumento das temperaturas.

Krüger \& Rossi (2011) propuseram um modelo de conforto térmico ao ar livre para subsidiar o planejamento urbano adequado ao clima. $\mathrm{O}$ monitoramento in situ, em campanhas com duas estações meteorológicas em áreas de pedestre, simultaneamente pesquisas baseadas e questionários de sensação térmica com cerca de 2000 transeuntes, no verão, primavera e inverno de 2009. O modelo preditivo de sensação térmica proposto para Curitiba, foi posteriormente calibrado com a colaboração direta dos desenvolvedores do índice UTCI (Bröde, Krüger, Rossi, \& Fiala, 2012).

Minella, Krüger, \& Rasia (2011), averiguaram o fator de visão do céu, Sky View Factor (SVF), como atributo urbano e seus efeitos sobre o clima intraurbano.

Silva (2012); Leal, Biondi, \& Batista (2014a; 2014b); Martini, Biondi, Viezzer, \& da Silva (2015), entre outros, analisam a influência da vegetação no microclima e no clima intraurbano por meio de métodos diferentes e em escalas distintas.

Schmitz \& Mendonca (2011; 2014); Minella \& Krüger (2017) usaram o mesmo software de simulação, ENVI-met, desenvolvido por Bruse e Fleer (1998) para a análise de cenários atuais e futuros de estratégias de planejamento urbano em Curitiba. Os cenários alternativos testados permitiram orientações para o planejamento urbano adequado ao clima e quantificaram padrões de uso e ocupação do solo para verificar a relação dos atributos urbanos com as condições climáticas.

Krüger, Minella, \& Matzarakis (2013), discutem quatro diferentes métodos de avaliação de comforto térmico urbano, em locais externos. Utilisam os dados históricos de diversas variáveis climáticas da cidade de Glasgow, Reino Unido em área urbana e em área rural.

Johansson, Thorsson, Emmanuel, \& Krüger (2014) compararam estudos realizados em 26 cidades do mundo, incluindo a 
cidade de Curitiba, com o objetivo de investigar dos instrumentos e métodos para o estudo de conforto térmico urbano. Os autores salientam a dificuldade de análise comparativa dos resultados devido a profusão de métodos e índices de avaliação utilizados e apontam a necessidade de sua padronização.

A significativa variabilidade do clima intraurbano em Curitiba resulta em distintos graus de conforto térmico no interior da mancha urbana. O predomínio das baixas temperaturas acarreta dificuldades enfrentadas pela população, sobretudo em sua parcela mais pobre, ante as condições climáticas locais.

O objetivo da investigação de carater interdisciplinar apresentada a seguir é avaliar a relação entre o clima intraurbano e as desigualdades socioespaciais geradas pelo desenvolvimento do AU-RMC como fator intensificador da vulnerabilidade da população em função das condições de vida no que diz respeito ao conforto térmico.

$\mathrm{O}$ artigo se baseia na tese de doutorado de Dumke (2007) e em suas atualizações visando embasar novas pesquisas sobre o tema e contribuir para a melhoria das condições de conforto térmico para todos os moradores, dentro e fora das habitações.

\section{Materiais e métodos}

\section{A área de estudo: o Aglomerado Urbano da Região Metropolitana de Curitiba (AU-RMC)}

Exceção entre as cidades brasileiras, Curitiba conta com um planejamento urbano permanente desde 1943. A cidade é conhecida internacionalmente como cidade exemplar. Diversos slogans foram criados pela administração municipal em referência ao planejamento urbano realizado e como estratégia para atrair investimentos para Curitiba, Capital de Primeiro Mundo, Cidade Modelo, Capital Ecológica e, mais recentemente, Capital Social. Contudo, contradizendo a imagem positiva veiculada sobre a cidade, Curitiba apresenta graves problemas socioambientais (Mendonça, 2004a).

A figura 1 situa o estado do Paraná no Brasil, a Região Metropolitana de Curitiba (RMC) no estado do Paraná e Curitiban

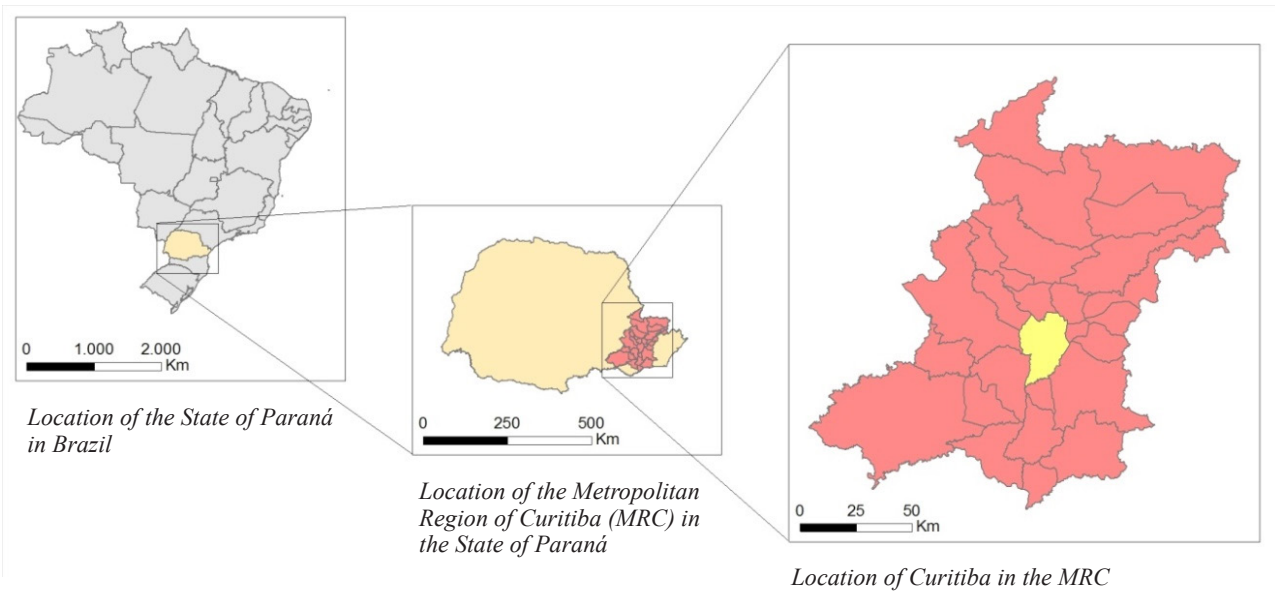

Figure 1: Localização de Curitiba (2525'40" S, 49²16'23”' W, e altitude de 934m) Fonte: IBGE (2011). Organização: Danni-Oliveira, Mendonça, Dumke \& Schmitz (2011)

Figure 1. Location of Curitiba ( $25^{\circ} 25^{\prime} 40^{\prime \prime} \mathrm{S}, 49^{\circ} 16^{\prime} 23^{\prime \prime} \mathrm{W}$, and altitude of $\left.934 \mathrm{~m}\right)$ Source: IBGE (2011). Based on Danni-Oliveira, Mendonça, Dumke \& Schmitz (2011) 


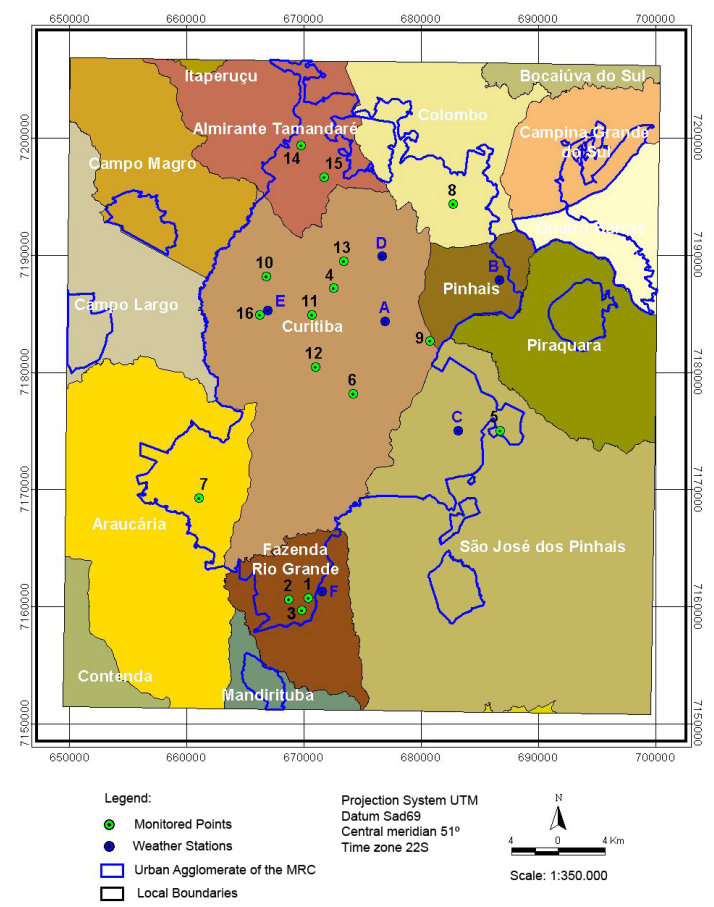

Figura 2. Localização do Aglomerado Urbano nos municípios da Região Metropolitana de Curitiba (RMC), pontos monitorados e estações meteorológicas. Fonte: Dumke (2007)

Figure 2. Location of the Urban Agglomerate in the municipalities of Metropolitan Region of Curitiba (RCM), monitoring points and meteorological stations. Source: Dumke (2007)

O êxodo rural provocado pela mecanização do campo na década de 1970 em paralelo à criação da Cidade Industrial de Curitiba atraiu um grande número de imigrantes em busca de oportunidades de trabalho. O movimento migratório foi realimentado nos anos 90, impulsionado pelo citymarketing e pela vinda de empresas montadoras de automóveis induzindo a um intenso crescimento da cidade e dos municípios circunvizinhos.

Curitiba passou a crescer em ritmo acelerado, vertical e arealmente, extrapolando os limites municipais e envolvendo cidades vizinhas: Almirante Tamandaré, Araucária, Campina Grande do Sul, Campo Largo, Campo Magro, Colombo, Fazenda Rio Grande, Pinhais, Piraquara, Quatro Barras e São José dos Pinhais. Essa mancha urbana de alta densidade demográfica e intensa relação funcional constitui o Aglomerado
Urbano de da Região Metropolitana de Curitiba (AU-RMC), com cerca de 3.094.000 habitantes em 2010, devendo elevar-se a 3.566 .000 habitantes em 2020 (IPARDES, 2010).

Os efeitos desta transformação de cidade foram intensos. A urbanização acelerada tornou necessária a elaboração e a implantação de novos Planos Urbanísticos e suas adaptações. Hoje a mancha urbana que se extende a partir do município-pólo (Curitiba) e constitui o AU-RMC, uma grande cidade polinucleada entremeada de áreas verdes, mesclando diferentes graus de densidade urbana.

No município-pólo, ao longo dos Setores Estruturais, criados para direcionar o crescimento da cidade e o fluxo de veículos, o zoneamento proporcionou a construção de altos edifícios que 
formam cânions urbanos alterando os campos térmicos, a iluminação natural, a ventilação e a qualidade do ar.

A configuração espacial de Curitiba hoje é marcada por essa maciça verticalização dos edifícios ao longo dos eixos estruturais, transformando de forma radical o sistema urbano existente anteriormente, causando um importante impacto ambiental na paisagem urbana e no clima intra-urbano, agravando o (des)conforto ambiental (Minella et al., 2011) e contaminação atmosférica (Danni-Oliveira, 2003), a falta de luz diurna (Krüger \& Suga, 2009), entre outros aspectos.

\section{O Estudo do Clima Urbano/Conforto Térmico: Métodos utilizados}

O estudo do clima do AU-RMC investiga as diferenciações térmicas intraurbanas, portanto se realiza no âmbito da Urban Canopy Layer (UCL) (Oke, 1988), que representa a interação entre a atmosfera e os elementos urbanos e que compreende o espaço entre o solo e o nível médio das coberturas das edificações.

O presente estudo, por suas características, demandou uma adaptação dos métodos usuais em climatologia urbana, para uma proposta mais abrangente. Encontrouse na proposta do Sistema Ambiental Urbano (SAU) de Mendonça (2004b; 2010), o fundamento teórico-metodológico adequado aos objetivos propostos. O SAU toma a cidade como um todo, um sistema complexo e aberto, composto de três subsistemas: o Subsistema Natural, o Subsistema Construído e o Subsistema Social. Da interação dos três subsistemas que correspondem ao output surgem os problemas socioambientais urbanos, para os quais devem ser buscadas soluções aplicáveis ao planejamento e à gestão socioambiental urbana. A influência direta da aplicação dessas soluções na qualidade de vida da população promove a continuidade do processo sistêmico, por meio dos mecanismos de feedback.

Utilizou-se ainda a metodologia criada por (Mendonça, 1995), para o estudo do clima urbano/intra-urbano de cidades de pequeno e médio porte, com adaptações para a escala metropolitana. Para compreender a composição de fatores que interagem entre si e simultaneamente no espaço e no tempo formando determinadas situações de conforto na cidade, esta metodologia propõe a imbricação de duas análises: a análise espacial e a análise temporal.

A análise espacial foi elaborada a partir da cartografia dos elementos do sítio urbano (hipsometria, declividades, orientação de vertentes do relevo e direção e velocidade de ventos de superfície) e do fato urbano (uso e ocupação do solo, neste trabalho também foram incluídos os aspectos da desigualdade socioespacial urbana: taxa de pobreza e adequação geral das habitações).

As cartas da Taxa de Pobreza e da Adequação Geral das Habitações foram cedidas pelo Instituto Paranaense de Desenvolvimento Econômico e Social, IPARDES e constam de IPARDES (2005). A partir dessas cartas, verificou-se a distribuição socioespacial das habitações.

A pobreza é definida como a condição em que a renda familiar mensal per capita é de, no máximo, meio salário mínimo, e a taxa de pobreza corresponde ao percentual de famílias nessa condição. O Índice de Adequação Geral das Habitações considera os critérios: abastecimento de água, escoamento sanitário, coleta de lixo e densidade de moradores por dormitório (IPARDES, 2005).

A relação entre os elementos do sítio urbano e do fato urbano resultou na Setorização de áreas de características urbanas relativamente homogêneas distribuídas na mancha urbana, caracterizando o ambiente urbano e orientando a geração da rede de monitoramento em campo.

A análise temporal foi realizada a partir da abordagem dinâmica do clima, do ritmo de sucessão habitual dos estados atmosféricos sobre os lugares, por meio da Análise Rítmica dos Tipos de Tempo, proposta por Monteiro nos anos 60/70 (Monteiro \& Mendonça, 2003), cuja disposição simultânea e sincrônica dos gráficos 
possibilita a comparação integrada dos parâmetros meteorológicos do lugar em sua variação diária e horária.

Aidentificação dos tipos de tempo demandou o acompanhamento da dinâmica dos centros de ação da atmosfera, por imagens de satélites e boletins meteorológicos no âmbito do zonal/regional e na escala sub-regional, bem como nas medições meteorológicas realizadas.

A escolha do período de inverno se deve as características do clima local, com desconforto térmico por frio durante todo o ano e principalmente no inverno. A Zona Bioclimática 1, que inclui o território de Curitiba é a mais fria das 8 zonas bioclimáticas brasileiras e representa apenas $0,8 \%$ do território brasileiro (ABNT, NBR 15220-3, 2005), entretanto eventuais recomendações para o planejamento urbano relacionadas à adequação climática de Curitiba podem ser utilizadas em cidades de outros países, com climas semelhantes.

A Termografia Infravermelha de Superfície (TIS), elaborada por tratamento da imagem Landsat 5 TM, de 20 de agosto de 2006, permitiu a visualização da distrituição intraurbana das temperaturas. A comparação direta dos dois conjuntos de dados (os obtidos por imagem de satélite e aqueles obtidos em campo) não se viabilizaria, ainda que fossem coletados simultaneamente, devido a diversidade de seus métodos. Porém, a TIS foi elaborada por meio da imagem de satélite

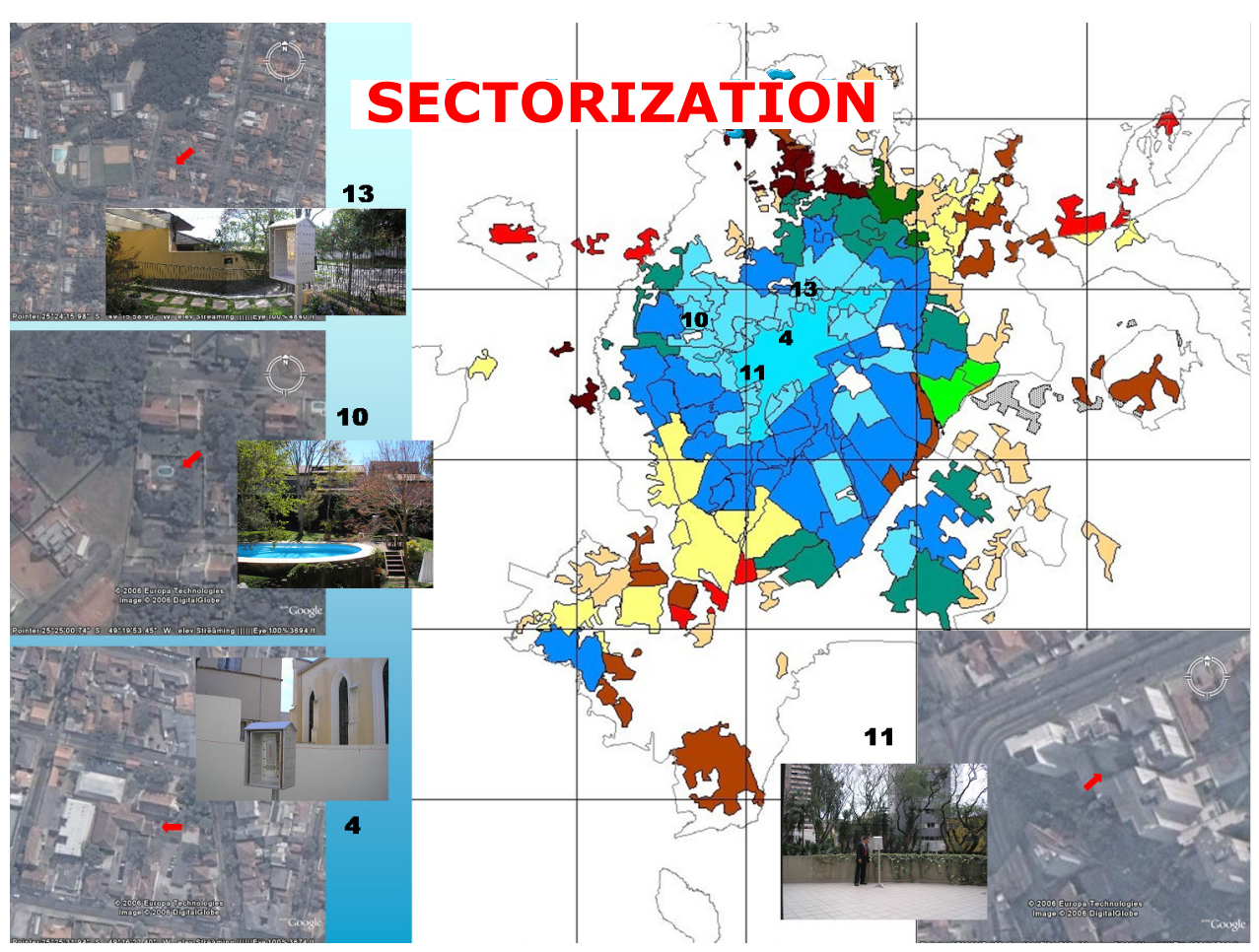

Figura 3. AU-RMC: localização dos pontos monitorados (melhores condições socioeconômicas) 4 e 11, 13, 10 Fonte: site Google Earth; e fotos do autor. Elaboração própria, (2016).

Figure 3. AU-RMC: location of sampling points (better socioeconomic conditions) 4 and 11, 13, 10 Source: site Google Earth; and photos from author. Own elaboration, (2016). 
tomada no dia anterior ao monitoramento de campo e, em conjunto com as cartas sinóticas, os boletins meteorológicos e a análise rítmica dos tipos de tempo, contribuiu para a observação da influência da temperatura de superfície na temperatura do ar (a $1,50 \mathrm{~m}$ de altura), monitorada no dia seguinte.

O monitoramento em campo foi realizado em 16 pontos selecionados a partir da análise espacial. A escolha dos dias de monitoramento visou à avaliação das condições de desconforto por frio, em episódios climáticos distintos, representativos do período de inverno local. Para cada um dos dias monitorados $(12,18,21$ e 29 de agosto 2006), foi realizada a análise sinótica e a análise rítmica dos tipos do tempo. Os dados de temperatura do ar $\left[{ }^{\circ} \mathrm{C}\right]$ e umidade relativa do ar $[\%]$ foram coletados in situ nos horários padronizados pela Organização Meteorológica Mundial OMM (6, 9, 15 e 21 horas), e comparados aos dados obtidos pelas estações meteorológicas. Foram também relacionados à carta de uso e ocupação do solo e à termografia infravermelha de superfície.

A figura 3 apresenta os ambientes monitorados na área de condições socioeconômicas mais favoráveis: n. 4, Centro Histórico; n. 10 e n. 13, áreas residencias dos bairros Santa Felicidade e Ahú, respectivamente; n. 11, o Setor Estrutural (eixo de transporte, verticalizado) no bairro do Batel.

Os dados sistematizados foram testados segundo dois parâmetros simples de conforto térmico:

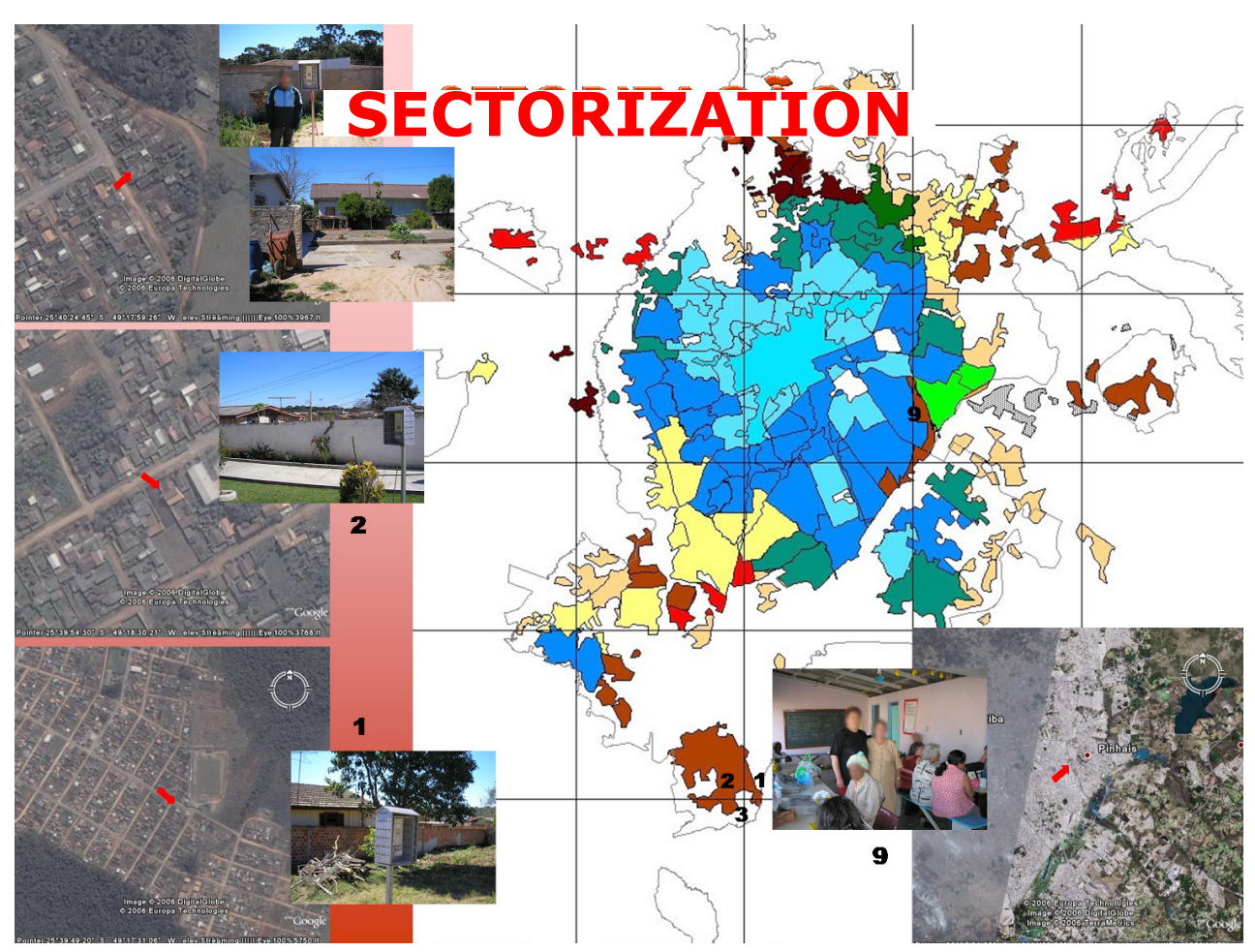

Figura 4. AU-RMC: localização dos pontos monitorados (condições socioeconômicas menos favoráveis) 1, 2, 3, 9 Fonte: site Google Earth; e fotos do autor. Elaboração própria, (2016)

Figure 4. AU-RMC: location of sampling points (lower socioeconomic conditions) 1, 2, 3, 9 Source: site Google Earth; and photos from author. Own elaboration, (2016) 
Método de Givoni (1992), adequado aos países em desenvolvimento;

A zona de conforto de Sorre (1984), de $16^{\circ} \mathrm{C}$ a $23^{\circ} \mathrm{C}$, adequada ao clima de Curitiba, associada ao cálculo da Temperatura Efetiva (TE) para a avaliação das condições termohigrométricas. A TE, utilizada para mostrar o desconforto por frio, é fornecida pela.

Equação: TE $=0,4(\mathrm{TS}+\mathrm{TU})+4,8$

Onde: TS e TU são temperaturas de bulbo seco e de bulbo úmido $\left[{ }^{\circ} \mathrm{C}\right]$

Os diferentes graus de desconforto térmico encontrados foram confrontados com a classificação das condições de vida/qualidade de vida nos locais amostrados. Verificou-se, assim, a relação entre o desconforto térmico e a vulnerabilidade social, objetivo dessa investigação. Neste artigo optou-se por apresentar apenas as análises referentes ao dia 21 de agosto de 2016, por ter sido o dia monitorado mais representativo do inverno local.

A figura 4 mostra os ambientes monitorados na área de condições socioeconômicas desfavoráveis. Os n. 1, 2 e 3, ao Sul, na periferia do município de Fazenda Rio Grande; o n. 9, ao leste de Curitiba, em área de habitação irregular no Bairro do Cajurú, próxima ao rio Iguaçú.

\section{Resultados}

\section{Quanto à distribuição socioespacial das habitações}

Observou-se a tendência de aumento da Taxa de Pobreza do município pólo em direção a periferia geográfica do Aglomerado Urbano, embora Araucária, São José dos Pinhais e Colombo apresentem uma distribuição heterogênea. Enquanto Curitiba, São José dos Pinhais e Araucária se destacam por apresentarem os melhores níveis de renda, os níveis mais críticos se verificam em Fazenda Rio Grande, Almirante Tamandaré e Piraquara. Alguns bairros de Curitiba apresentam simultaneamente o alto número de famílias de estrato superior e o elevado número de famílias pobres, devido à presença de favelas. Segundo o IPARDES (2005), em 2003, do total de famílias pobres da RMC, cerca de $40 \%$ se concentram em Curitiba e $45 \%$ nos outros municípios do Aglomerado Urbano. Entre estes, Piraquara apresenta a maior taxa de pobreza com $23,17 \%$ e São José dos Pinhais a menor: $14,03 \%$. No outro extremo, Curitiba concentra 82,64\% do total de famílias que se encontram o estrato superior (renda per capita acima de 3 salários mínimos) na RMC.

A distribuição das condições de adequação geral das habitações evidencia a desigualdade socioespacial na mancha urbana. O município pólo, mesmo com disparidades internas, apresenta a mais elevada proporção de habitações com adequação geral, que, em geral, decresce em direção à periferia da mancha urbana, mas de forma heterogênea. Considerandose apenas os municípios vizinhos a Curitiba, a maior proporção de adequação das habitações se localiza nas regiões centrais de Araucária, Colombo e São José dos Pinhais, seguidos de Pinhais. Já as mais baixas proporções se encontram nos municípios ao Sul, além dos municípios de Almirante Tamandaré e Campo Largo, ao Norte e a Noroeste de Curitiba. De acordo com o IPARDES (2005), no ano de 2003 o aglomerado urbano possuía no total 195.658 domicílios inadequados, dos quais 95.573 se encontravam no município pólo. Os restantes se concentravam principalmente nos municípios de São José dos Pinhais e Colombo, seguidos de Almirante Tamandaré, Araucária.

Quanto ao uso do solo (figura 5), três conjuntos de ambientes se distinguem na mancha urbana em relação às condições de conforto térmico:

A área mais adensada/verticalizada, o Centro Histórico e os Setores Estruturais (em vermelho) se inserem nas áreas mais centrais e adensadas da mancha urbana e, portanto mais sujeitos ao clima urbano/ ilha de calor. A alta densidade urbana se constitui armazenadora de calor; e a rugosidade reduz a ventilação na canopy layer. 
No Centro Histórico, a limitação da altura das edificações pela legislação permite a melhor insolação do solo e das edificações. Tais características conferem a este ambiente as condições de menor desconforto térmico por frio, entre todos os ambientes monitorados e uma maior amplitude térmica entre os ambientes da área mais adensada. Em oposição, os Setores Estruturais são as áreas mais verticalizadas da cidade e onde, frequentemente, a insolação dos pavimentos inferiores e do solo é prejudicada notadamente no inverno: o ângulo da altura do Sol não permite seu rápido aquecimento no período diurno.
A inércia térmica dos materiais e a troca térmica entre os edifícios dificultam a perda de calor para a atmosfera à noite, e são responsáveis pela menor amplitude térmica do Batel entre os ambientes avaliados.

As áreas urbanas não adensadas (em rosa) apresentam condições de conforto intermediárias e se situam em bairros de Curitiba ou em municípios bastante urbanizados e industrializados: ao Sul da mancha urbana, Araucária, ao Norte, Colombo, de características do sítio parecidas. O ambiente no bairro Cajuru, na parte Leste dentro do município de

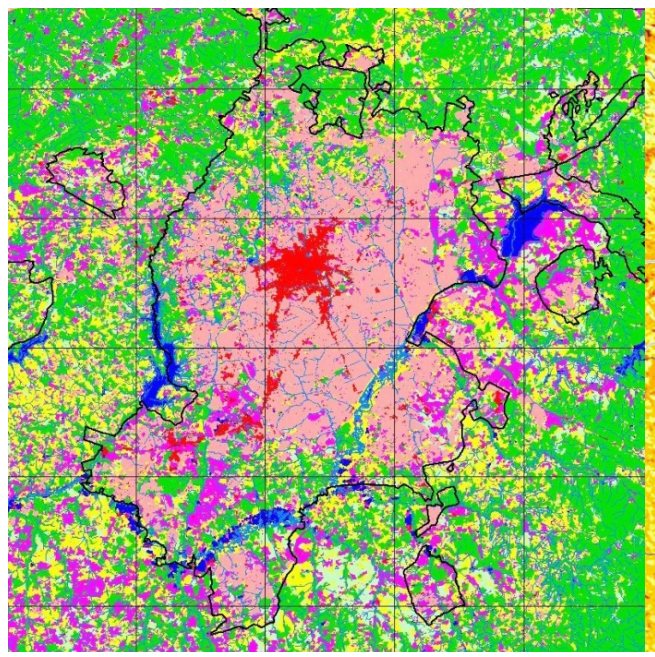

Legend: Drainage Network
$\square$ RMC Urban Agglomerate

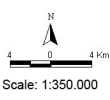

Figura 5. Aglomerado Urbano da Região Metropolitana de Curitiba (AU-RMC): Uso e Ocupação do Solo. Fonte: Imagem Multiespectral do satélite LANDSAT-7 ETM +, 220-078, 27 de setembro de 2002

Figure 5. Urban Agglomerate of the Metropolitan Region of Curitiba (AU-RMC): Land Use. Source: Multispectral images of satellite LANDSAT-7

ETM +, 220-078, September 27th 2002

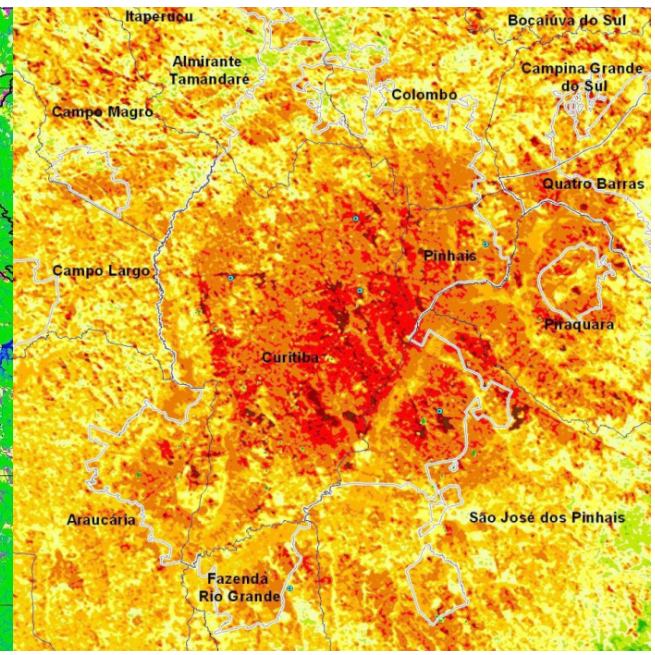

Temperatura [ $\mathrm{C}]$

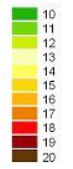

Figura 6. AU-RMC: Termografia Infravermelha de Superfície, 20.agosto.2006. Fonte: INPE, Instituto Nacional de Pesquisa Espacial. Imagem LANDSAT-5 TM, 220-078, 20 de agosto de 2006. 10:00 hr.

Figure 6. AU-RMC: Infrared Surface Thermography, August 20th, 2006. Source: INPE - National Institute of Space Research. Image LANDSAT-5 TM, 220078, August 20th 2006. 10:00 hrs. 
Curitiba, é excessão, devido ao baixo desconforto por frio e alto desconforto pela elevada amplitude térmica diária. Situa-se na área urbana não adensada, em área de ocupação irregular e de preservação ambiental: fundo de vale do Rio Iguaçu, local de baixa altitude e alta vulnerabilidade socioambiental (sujeito a enchentes).

O terceiro conjunto, nos limites Sul, Leste e Norte da mancha urbana, apresenta as condições menos favoráveis aos moradores. Suas condições climáticas se devem a baixa densidade e a localização próxima à área rural associadas às características do sítio, a conformação do relevo concorre para intensificar o desconforto por baixas temperaturas e por grande amplitude térmica. A formação de um corredor de vento sentido Sudoeste-Nordeste favorece a entrada das frentes frias e massas de ar frio que frequentemente entram na região vindas desta orientação, deixando desprotegidas as periferias urbanas Sul e Norte. O mesmo ocorre na periferia de São José dos Pinhais, em fundo de vale Leste-Oeste, sentido preferencial do vento, em relação ao vento Leste, devido a falha existente neste trecho da Serra do Mar.

As condições sinóticas. No dia 20 de agosto de 2006, as condições sinóticas da América do Sul e da Região Sul do Brasil apresentavam uma dinâmica atmosférica nos âmbitos zonal e regional sob a atuação de dois sistemas atmosféricos frontais, a massa de ar seco e frio ( $\mathrm{MPa}$ ) na Região Sul e os centros de alta (A) e de baixa (B) pressão. Conforme o CPTEC/INPE (2006), os dois sistemas frontais se acoplaram: o ciclone associado à frente fria na altura do Rio de Janeiro e o outro sistema mais ao Sul. A incursão da intensa massa de ar frio provocou nos dias 20 a 22 uma queda brusca nas temperaturas em toda a região.

A termografia de infravermelha de superfície (figura 6), obtida por meio da imagem Landsat 5, no dia 20 de agosto de $2006,10 \mathrm{~h}$, apresenta uma visão detalhada das condições climáticas distintas na escala intraurbana de Curitiba. Quanto às características urbanas, observou-se a influência da cobertura da superfície em função do uso do solo (mineralizada, vegetada etc.), da geometria, da estrutura e da densidade urbana e do calor antropogênico. Comparando-se a termografia infravermelha de superfície (figura 6) à carta de uso do solo (figura 5), observa-se:

A mancha urbana se evidencia nas superfícies mais aquecidas dos solos mineralizados (de maior albedo), com temperaturas entre $16^{\circ} \mathrm{C}$ e $20^{\circ} \mathrm{C}$, no momento do imageamento. Forma-se uma IC de $7^{\circ} \mathrm{C}$ de intensidade em relação ao entorno rural imediato, e de $11^{\circ} \mathrm{C}$ de intensidade ao se considerar toda a área imageada. As temperaturas mais baixas ocorrem em áreas rurais de elevada altitude, topografia variada e vegetação densa, ao Sudeste, ao Norte e a Noroeste.

Não são as áreas urbanas mais verticalizadas a apresentar as temperaturas mais elevadas, o que se explica pelo sombreamento dos edifícios que impedem as superfícies de serem atingidas pela radiação solar direta nesta hora do dia. Ainda assim, as temperaturas são bastante elevadas nestas áreas, devido à produção de calor antropogênico, à maior rugosidade e à massa térmica das edificações.

Salientam-se as ilhas de frescor sobre os parques urbanos, as áreas verdes e os fundos de vale, bem como as temperaturas amenas e homogêneas das massas de água devido à sua inércia térmica e à evaporação. As temperaturas mais elevadas ocorreram em áreas de alto grau de urbanização e amplas superfícies asfaltadas: os aeroportos de São José dos Pinhais e do Bacacheri, os setores industriais a oeste (Cidade Industrial), a sul (Araucária) e leste (São José dos Pinhais) e as principais vias de transporte.

As medições in situ (figura 7), em 21 de agosto de 2006, às 6 horas, ocorreram sob o domínio de forte Massa Polar Atlântica (Mpa) que avançava da Argentina e do Uruguai sobre a Região Sul. A ausência de nuvens e os ventos calmos favoreciam 

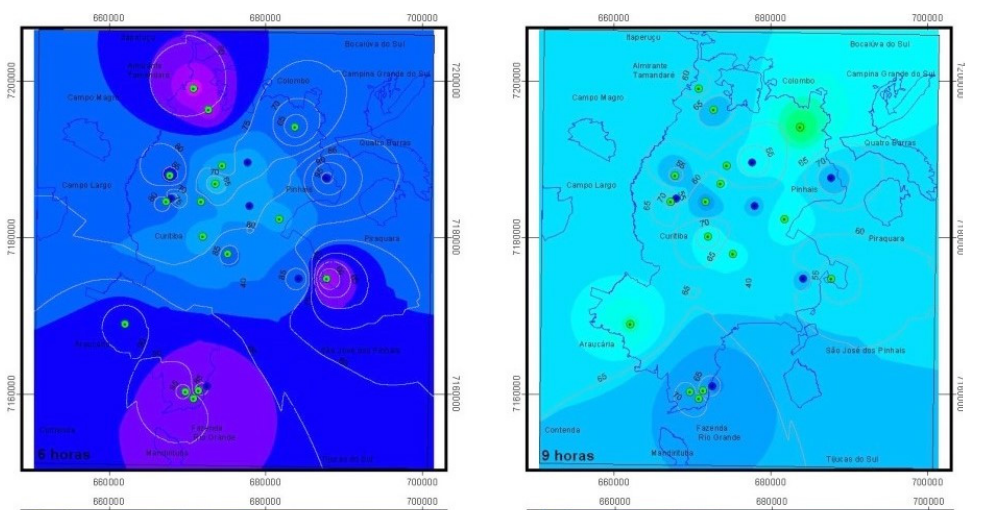

Temperature $\left[{ }^{\circ} \mathrm{C}\right]$
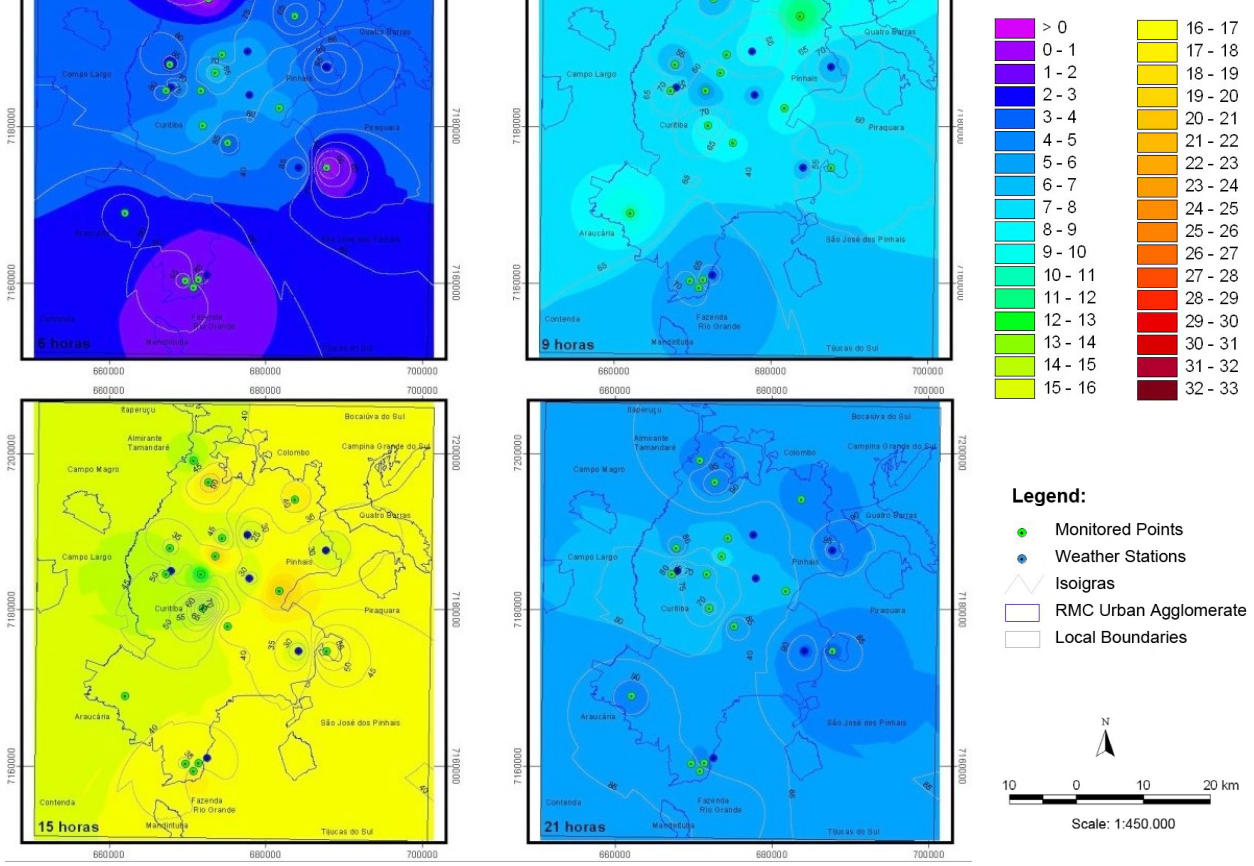

Figura 7. Aglomerado Urbano da Região Metropolitana de Curitiba (AU-RMC): Isolinhas 21 de agosto de 2006, às 6, 9, 15 e 21hs. Fonte: Base Cartográfica: SEMA, Mineropar (2004)

Figure 7. Urban Agglomerate of the Metropolitan Region of Curitiba (AU-RMC): Isolines for August,

21st 2006, at 6, 9, 15 and 21 o'clock. Source: Cartographic Basis: SEMA, Mineropar (2002)

a rápida redução das temperaturas. O início do dia foi marcado pelo frio intenso, mas durante o dia houve grande amplitude térmica e baixa umidade do ar (que às 17 horas atingiu 26,8\%).

A figura 7 apresenta as isolinhas de temperatura para o dia 21 de agosto 2006 às $6,9,15$ e 21 horas, indicando adinâmica das ilhas de calor e das ilhas de frescor ao longo do dia no AU-RMC. $\mathrm{Na}$ carta das 6 da manhã destaca-se uma nítida IC com $7^{\circ} \mathrm{C}$ de intensidade sobre grande parte de Curitiba, extravasando para o Leste e abrangendo uma parcela dos municípios de Pinhais, Piraquara e São José dos Pinhais, justamente sobre a mancha urbana mais evidenciada. As temperaturas apresentaram-se bem mais baixas mais à Leste (periferia de São José dos Pinhais), Norte (Almirante
Tamandaré) e Sul (Fazenda Rio Grande. Às 6 horas o município de Almirante Tamandaré (ao Norte) apresentou a mais baixa temperatura de todo o trabalho de campo: $-0,3^{\circ} \mathrm{C}$ e a maior amplitude térmica diária entre os locais monitorados nesse dia: $18,5^{\circ} \mathrm{C}$. A menor amplitude térmica diária ocorreu na área verticalizada do Setor Estrutural no Batel, com intensidade de $7,2^{\circ} \mathrm{C}$. As temperaturas mais elevadas ocorreram no Centro Histórico: $7,3^{\circ} \mathrm{C}$ às 6 horas e $20,3^{\circ} \mathrm{C}$ às 15 horas. $\mathrm{O}$ Batel e o Centro Histórico se situam na área urbana mais adensada.

No dia 21 de agosto de 2006, sob o domínio de forte MPa e assim, de grande amplitude térmica, a tendência da cidade foi se configurar como ilha de calor à noite e ilha de frescor durante o dia. As IC às 6 e às 21 horas foram de menor intensidade 


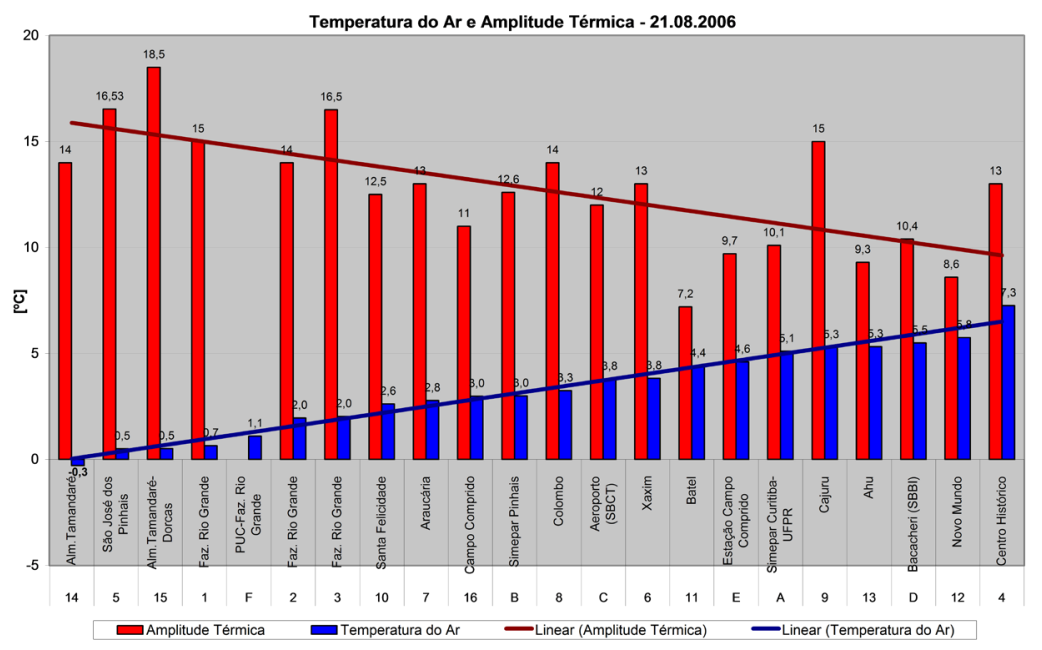

Figura 8. Aglomerado Urbano da Região Metropolitana de Curitiba (AU-RMC): Temperatura do Ar $\left[{ }^{\circ} \mathrm{C}\right]$ às $6 \mathrm{~h}$ e Amplitude Térmica Diária $\left[{ }^{\circ} \mathrm{C}\right] .21$ de agosto de 2006. Fonte: Elaboração própria (2016)

Figure 8. Urban Agglomerate of the Metropolitan Region of Curitiba (AU-RMC): Air Temperature $\left[{ }^{\circ} \mathrm{C}\right]$ at 6 am and Daily Thermal Amplitude $\left[{ }^{\circ} \mathrm{C}\right]$. August, 21st 2006. Source: Own elaboration (2016)

$\left(7^{\circ} \mathrm{C}\right.$ e $\left.4,1^{\circ} \mathrm{C}\right)$ do que às IF as 9 e 15 horas (respectivamente $7,1^{\circ} \mathrm{C}$ e $8,7^{\circ} \mathrm{C}$ ).

Constatou-se como característica local, que além do desconforto por frio, também a variabilidade diária das temperaturas, traduzida parcialmente pela amplitude térmica, é frequentemente relatada como fator de desconforto térmico pela população.

A figura 8 confronta os dados de temperaturas (tomadas às 6 horas) aos dados de amplitude térmica diária (6 e 15 horas) no dia 21 de agosto. Verifica-se uma certa coincidência entre os locais que apresentaram as temperaturas mais baixas e aqueles de maiores amplitudes térmicas diárias. Observam-se os maiores graus de desconforto por frio nos municípios de Almirante Tamandaré, São José dos Pinhais e Fazenda Rio Grande; as maiores amplitudes térmicas também. Esta correspondência é confirmada pelas linhas de tendência.

Para a melhor compreensão da variação de temperaturas durante o dia, foram elaborados gráficos senoidais (Kruger, 2002). Tais gráficos elaborados para o dia 21 de agosto de 2006, visam à análise comparativa das condições climáticas e de conforto térmico nos locais avaliados, com distintas características naturais, construídas e de condições e qualidade de vida.

A figura 9 mostra a incidência de temperaturas mais baixas e a maior amplitude térmica nas áreas de condições e qualidade de vida mais desfavoráveis (em marrom). Em oposição, as áreas de melhores condições sociais (em azul claro) apresentaram as temperaturas mais elevadas, sobretudo nos horários mais críticos, às 6 horas e às 21 horas. Também nestas últimas áreas, ocorrem as menores amplitudes térmicas.

Assim, evidencia-se que a diferenciação espaçotemporal das condições climáticas do AU-RMC se relaciona a distribuição socioespacial das habitações. O desenvolvimento urbano em Curitiba conduziu, em geral, a intensificação da vulnerabilidade da população quanto ao conforto térmico. Mas, quais seriam as tendências do clima e seus impactos nessa vulnerabilidade?

As diferenciações entre as duas áreas de melhores condições de vida Centro 


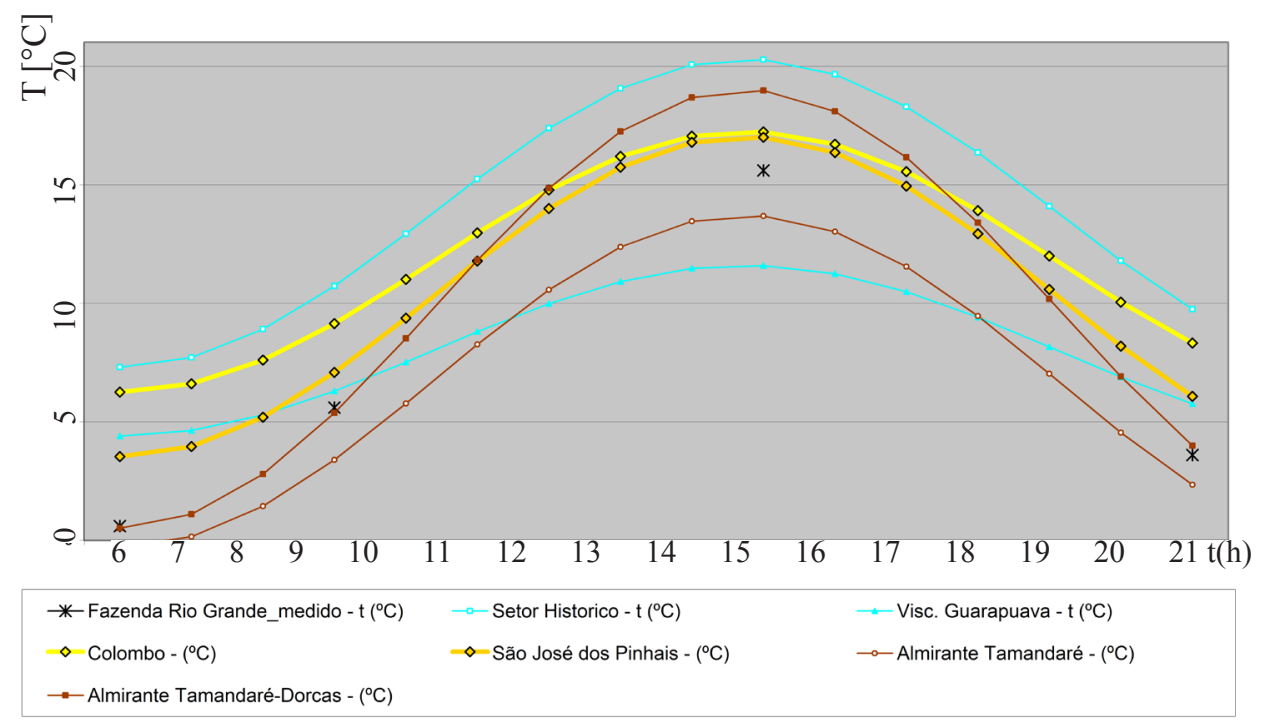

Figura 9. Temperatura do ar nos pontos monitorados das 6 às 21 horas. Os pontos monitorados em áreas de condições de vida mais favoráveis (representadas em azul), menos favoráveis (marrom) e áreas de condições de vida intermediárias (amarelo). Fonte: Elaboração própria (2016)

Figure 9. Air temperature at monitored points from $6 \mathrm{am}$. to $9 \mathrm{pm}$. The points monitored in areas of more favorable conditions of quality of life (represented in blue), less favorable areas (brown) and areas of intermediate conditions/life quality (yellow). Source: Own elaboration (2016)

Histórico e Batel, já foram mencionadas. Os dois pontos localizados em Almirante Tamandaré e Almirante Tamandaré Dorcas, situados em áreas de condições de vida mais desfavoráveis, ao Norte de Curitiba, encontram-se, respectivamente, nas faixas de altitude de 950-980 m, e de 920-950 $\mathrm{m}$, mas não diferem quanto a reduzida declividade do sítio e a baixa velocidade de vento. As características construídas também diferem: embora ambas se situem na margem da Rodovia dos Minérios (PR092), o ponto de monitoramento mais ao Norte se situa em local mais protegido do vento do que o da comunidade Dorcas.

Entre as áreas de condições sociais intermediárias, o ponto de monitoramento em Colombo se localiza em área urbana mais adensada que o de São José dos Pinhais.

As características naturais dos dois locais semelhantes quanto à altitude (890-920 $\mathrm{m})$, declividades $(0 \%$ a $5 \%)$, e velocidade do vento (calmaria), no entanto diferem em relação à orientação: o ponto monitorado em Colombo se situa na vertente Norte, enquanto o de São José dos Pinhais, se situa na vertente Sul.

Como se verificou, as condições climáticas se apresentaram diferenciadas nas paisagens intraurbanas analisadas, influenciadas pelas características naturais do sítio e pelas características urbanas, conforme a relevância de cada elemento na construção das condições de conforto térmico. Em relação aos graus de conforto encontrados, há certa coincidência com a distribuição socioespacial das habitações.

A carta de condições de conforto térmico relacionadas às condições e qualidade de vida do au-rmc (figura 10), mostra a carta de Setorização (obtida pela sobreposição das diversas cartas: de elementos do sítio, do uso do solo e de desigualdades socioespaciais: pobreza e adequação das habitações). Os 23 setores representados em 
polígonos de cor cinza foram estabelecidos conforme as características do sítio e do uso do solo. Esses setores foram então agrupados em onze cores, que indicam as suas condições e qualidade de vida. A escala de cores representa a variação: do verde claro (condições e qualidade de vida mais favoráveis) ao vermelho escuro (menos favoraveis). Sobre a carta de setorização são ainda representados os graus de desconforto térmico por frio (círculos) e por elevada amplitude térmica (triângulos) nos locais avaliados. A dimensão do símbolo, representa a intensidade do desconforto térmico.

Os círculos representam o número de graus centígrados $\left[{ }^{\circ} \mathrm{C}\right]$ abaixo da zona de conforto térmico de Sorre $(1984)$, de $16^{\circ} \mathrm{C}$ a $23^{\circ} \mathrm{C}$, conforme a Temperatura Efetiva, TE. Os triângulos representam em ordem crescente os graus de desconforto térmico por amplitude térmica diária e foram calculados a partir da temperatura de bulbo seco (Tbs).
A carta evidencia a tendência de coincidirem nos mesmos locais as mais graves condições de desconforto segundo os dois parâmetros avaliados: o frio e as amplitudes térmicas elevadas. Como exceção, em situação contraditória, o Cajuru apresentou simultaneamente os menores graus de desconforto por frio e as maiores amplitudes térmicas. Provavelmente debido ao elevado número de casas térreas e alta taxa de impermeabilização, além da sua localização quase central na manha urbana.

Também se verifica com clareza que, neste dia frio de inverno:

Três dos quatro ambientes monitorados localizados nas áreas de mais favoráveis condições e qualidade de vida apresentaram as melhores condições de conforto térmico (menores graus de desconforto por frio e menores amplitudes térmicas diárias), no Ahu, no Centro Histórico e no Batel; o quarto
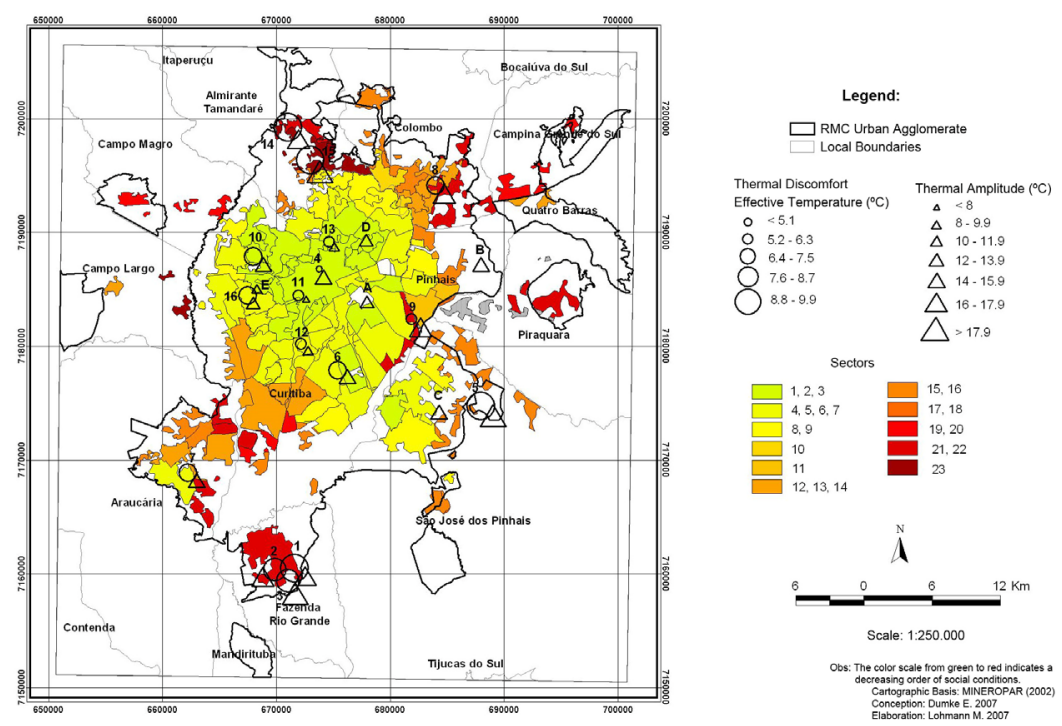

Figura 10. AU-RMC: Condições de conforto térmico relacionadas às condições de vida e qualidade de vida em 21.de agosto.de 2006. Fonte: Elaboração própria (2016)

Figure 10. AU-RMC: Thermal comfort conditions related to life conditions and quality of life on August. 21st, 2006. Source: Own elaboration (2016) 
ambiente, em Santa Felicidade, talvez devido à sua alta porcentagem de áreas verdes, apresentou graus de conforto térmico intermediários;

Três dos quatro ambientes monitorados situados nas áreas de condições e qualidade de vida intermediárias apresentaram também graus intermediários de conforto térmico segundo os dois parâmetros avaliados, no Campo Comprido, no Xaxim e no município de Araucária; o quarto ambiente, no Novo Mundo, situado em uma área um pouco mais adensada, apresentou as melhores condições de conforto térmico;

Dos dois ambientes monitorados considerados de condições sociais entre intermediárias e baixas, Colombo mostrou graus intermediários de conforto térmico e São José dos Pinhais apresentou baixos graus de conforto térmico;

Cinco entre seis ambientes localizados em áreas de condições e qualidade de vida menos favoráveis, apresentaram também as menos favoráveis condições de conforto térmico, os dois situados em Almirante Tamandaré e os três situados em Fazenda Rio Grande; o sexto ambiente, o Cajuru, apresentou baixo grau de desconforto por frio, porém elevado desconforto por amplitude térmica.

Note-se entre os todos os dezesseis ambientes avaliados, aqueles situados no município de Almirante Tamandaré apresentaram as condições menos favoráveis tanto em relação aos parâmetros de conforto térmico quanto aos indicadores de condições e qualidade de vida investigados.

Assim, é inegável haver no AU-RMC uma relação entre a estratificação socioespacial e as condições de conforto térmico dos habitantes, uma vez que em relação ao clima intraurbano, as classes menos favorecidas habitam lugares de maior rigor climático.

\section{Discussão dos resultados}

As análises do clima e do tempo no inverno de 2006 indicaram que em Curitiba, dadas as suas dimensões e a heterogeneidade de suas características do sitio natural e do construto urbano, não se configura a priori apenas uma IC. Sua estrutura e forma urbanas diferem daquelas das cidades tradicionais, nas quais a área comercial e verticalizada se localiza no centro, ao redor do qual a densidade urbana se reduz gradativamente.

O AU-RMC, ao contrário, se caracteriza pela morfologia urbana orientada por eixos estruturais verticalizados no município pólo e pela urbanização polinucleada como um todo, mesclando diferentes graus de densidade urbana entremeados de áreas verdes distribuídas de forma diferenciada.

Do mesmo modo, a significativa diversificação do sítio urbano, mostrouse relevante na distribuição intraurbana da temperatura do ar. Assim, os resultados encontrados corroboram as análises de Mendonça e Dubreuil (2006) e as afirmações de Eliasson (2000) sobre a variabilidade do clima intraurbano e sua relação ao entorno rural.

Esta dinâmica ocorreu não só no dia 21 de agosto, mas nos quatro dias de monitoramento, as 6 e às 21 horas, sob distintas condições sinóticas: os domínios de Massa Tropical Continental, MTc, Frente Polar Atlântica, FPa e Massa Polar Atlântica, $\mathrm{MPa}$.

As condições climáticas mostraramse diferenciadas nas diversas paisagens intraurbanas analisadas, conforme as características do sítio e do fato urbano.

Entre os elementos naturais do sítio, constatou-se a maior influência da altitude, da exposição aos ventos e da orientação das vertentes. Alguns destes elementos se associaram à ocupação, pois a cidade se desenvolveu a partir dos locais mais planos, 
de menor altitude, junto aos rios. Os locais de maiores altitudes, de topografia mais variada e difícil ocupação se encontram na periferia, ao Norte e a Noroeste do AU-RMC. Os corredores de vento, devido à topografia, atingem as áreas periféricas ao Norte, ao Leste e ao Sul, favorecendo a queda das temperaturas nestes locais. O centro está mais protegido do frio tanto pelo relevo como pela configuração urbana.

A correspondência entre o predomínio de tipos de uso do solo e alguns agrupamentos de ambientes de determinadas condições climáticas intraurbanas se deve a uma conjugação de fatores formadores do clima relacionados aos tipos de uso do solo (como a estrutura e a configuração urbanas, o albedo e o calor antropogênico) e sua interação às características do sítio, que ao mesmo tempo condicionam parcialmente a ocupação do solo e as formas de urbanização e interferem na produção do clima. É provável que esta seja a razão da correspondência constatada nos locais entre as condições de desconforto segundo os dois parâmetros avaliados: o frio e as amplitudes térmicas elevadas.

Segundo Stewart et al. (2014), as diferenças térmicas nos padrões de uso e ocupação do solo que influenciam a temperatura do ar (entre 1 e $2 \mathrm{~m}$ de altura), decorrem sobretudo da relação altura e espaçamento das construções, área permeável, densidade de vegetação arbórea e umidade do solo. Utilizando esses criterios, os autores encontraram 17 padrões ou zonas climáticas locais.

No AU-RMC os padrões de uso e ocupação do solo nem sempre são encontrados de forma tão homogênea como na classificação desses autores, embora permita aproximações. Pelas dimensões e complexidade do AURMC optou-se por incluir na classificação de uso e ocupação do solo: áreas urbanas de alta densidade (verticalizada e centro histórico); áreas urbanas não adensadas; corpos d'agua; solo exposto; cultivo; vegetação esparsa e vegetação densa.
Comparavel à Local Climate Zone, LCZ 1 de Stewart et al. (2014), adensada e constituída por arranha-céus, o Batel se situa no Setor Estrutural, que se caracteriza por uma extensa área linear de edifícios de grande altura e alta densidade. Destaca-se o sombreamento do solo e dos pavimentos mais baixos, gerado pelos edifícios. O baixo índice de fator de visão do céu, ou Sky View Factor (SVF), devido ao conjunto de edifícios altos e compactos, propicia uma maior retenção de radiação infravermelha nos cânions urbanos. O intenso trânsito de veículos nos Setores Estruturais gera grande liberação de calor sensível e latente pela combustão de comustíveis para o transporte urbano. A pequena amplitude térmica pode ser explicada pela massa térmica gerada pela alta densidade urbana, o aumento da rugosidade, a alta taxa de impermeabilização e a escassez de área verde entre outros fatores geradores da Ilha de Calor (IC).

Segundo Stewart et al. (2014), a grande absorção e libzeração tardia de calor por edifícios e superfícies pavimentadas na cidade como fator de intensificação da $\mathrm{IC}$, se deve não apenas às propriedades térmicas dos materiais, mas também à radiação solar e infravermelha e às perdas de convecção reduzidas na canopy layer onde o fluxo de ar é retardado.

Comparavel às LCZ 2 e 3 de Stewart et al. (2014), áreas adensadas de altura média e baixa, encontra-se a área de amostragem no Centro Histórico. De modo geral, observou-se nos dias monitorados que as temperaturas mais altas ocorrem nas áreas urbanas mais adensadas, porém, não verticalizadas. Assim, os menores graus de desconforto térmico por frio ocorreram nas áreas mais centrais e mais densamente urbanizadas, como o Centro Histórico, onde a limitação da altura dos edifícios permite maior incidência da radiação solar. O solo é bastante impermeabilizado e as árvores são dispersas. 
Para Stewart et al. (2014), a maior absorção de radiação solar não é somente devida ao menor albedo dos materiais urbanos, mas também por reflexão múltipla e radiação através da construção de superfícies verticais nas cidade. Além disso, a substituição dos solos úmidos por pisos impermeáveis, a supressão da vegetação e a redução da evaporação das superfícies, fazem com que a maior parte da radiação solar absorvida na superfície seja convertida em formas de calor sensíveis e não latentes.

No AU-RMC, constatou-se que as temperaturas mais baixas e maiores amplitudes ocorrem na periferia Norte, Sul e Leste. A associação entre os elementos naturais, construídos e sociais se mostrou particularmente crítica nesses locais onde a topografia forma corredores naturais de vento e que se encontram nas proximidades dos limites da macha urbana: ao Norte do AU-RMC, em Almirante Tamandaré; ao Sul, em Fazenda Rio Grande; e ao Leste, junto ao rio, em São José dos Pinhais.

Destacam-se, nesta distribuição geral das condições termohigrométricas, os efeitos da geometria e da densidade urbana (também relacionada ao calor antropogênico), bem como da distribuição das áreas vegetadas, da altitude e da variação topográfica.

Todavia, não se pode ignorar a influência recíproca entre as mudanças climáticas globais, devido a causas naturais ou antropogênicas, e o clima urbano (Casagrande, Junior, \& Mendonça, 2011).

$\mathrm{O}$ aumento médio de temperatura de $1,9^{\circ} \mathrm{C}$ em Curitiba para o período de 32 anos, encontrado por Rossi et al. (2009) na atualização do Ano Climático de Referência para a década 1998-2007, é significativo. Embora tenha sido verificado um aumento da porcentagem de conforto (entre $18^{\circ} \mathrm{C}$ e $29^{\circ} \mathrm{C}$ ) em 2007 em $20 \%$ em relação a 1969 , com o aumento das temperaturas.
É possível que a elevação das temperaturas no AU-RMC tenha sido causada principalmente pelo acelerado crescimento urbano de Curitiba e sua conurbação com as cidades vizinhas, que se deu justamente neste período. Entre 1969 e 2006 a população da mancha urbana aumentou em cerca de quatro vezes (IPARDES, 2010). Mas o desconforto térmico por frio em Curitiba continua intenso e predominando com $53.30 \%$ das horas anuais.

No caso de se confirmar a elevação das temperaturas em Curitiba e no âmbito planetário, o desconforto por frio diminuirá. Porém, as desigualdades sociais quanto a vulnerabilidade social ao clima com respeito ao conforto térmico em Curitiba pode até mesmo se agravar com o aquecimento gerado pelo crecimento da cidade e sua ilha de calor, devido a tendência de periferização das classes menos favorecidas diante da especulação imobiliária.

Em outra perspectiva, analisando o conforto térmico no interior de habitações de interesse social, Krüger (2015) questiona se a ilha de calor (IC) em Curitiba seria benéfica aos moradores no AU-RMC. Segundo o autor, a IC aumentaria a porcentagem das horas de conforto térmico em locais abertos no inverno diminuindo o desconforto térmico por frio. Mas, a elevação das temperaturas acarretaria um desconforto térmico por calor proporcionalmente maior dentro das habitações, sobretudo no verão, prejudicando o sono dos moradores durante a noite, quando o efeito da IC é mais intenso.

Porém, até o presente, sabe-se que em Curitiba e no AU-RMC, em geral, morrese de frio, não por calor. Entretanto as estratégias bioclimáticas visando $\mathrm{o}$ conforto térmico precisam ser adotadas tanto para o planejamento urbano como para as habitações, no verão e no inverno, dentro e fora das habitações. 
Neste trabalho, foi possível identificar algunas recomendações ao planejamento urbano no AU-RMC para melhoria do conforto térmico no inverno, em áreas abertas:

Identificaram-se as estratégias gerais de condicionamento passivo mediante a aplicação da metodologia de Givoni (1992) aos resultados encontrados para o AU-RMC nos locais monitorados em 21 de agosto de 2006, quando ocorria um episódio de frio intenso, frequente nesta cidade: a estratégia de aquecimento artificial foi requerida em $72 \%$ das medições realizadas no dia, mas é disponível apenas para parte da população do AU-RMC; e as estratégias de aquecimento solar passivo e massa térmica para aquecimento e aquecimento solar foram contempladas por $8 \%$ e $14 \%$ das medições deste dia, respectivamente.

Desta forma, corrobora-se a importância de se considerar as estratégias de aquecimento solar passivo e de massa térmica para aquecimento com aquecimento solar no desenvolvimento do planejamento urbano do AU-RMC, por meio de uma revisão aprofundada dos critérios que estabelecem os afastamentos entre as edificações, considerando-se sua relação com a altura das mesmas e a orientação do Sol e do vento. Ainda que o período analisado tenha sido de pouca umidade, Curitiba se caracteriza pelo clima frio e úmido. Portanto, recomenda-se certa porosidade entre as edificações para permitir a ventilação necessária inclusive nos meses de inverno, porém, sobretudo nesta estação, deve-se evitar a canalização do vento, o que também pode ser previsto no planejamento urbano.

Estas estratégias devem ser orientadas e viabilizadas para todas as parcelas da população, visando à redução do gasto energético em aquecimento artificial pelas classes mais abastadas e reduzindo o desconforto das parcelas mais desfavorecidas da população. Além da imprescindível melhoria das condições de vida das parcelas menos favorecidas, é necessário o provimento de energia nas áreas do AU-RMC que atualmente estejam desprovidas, de forma a viabilizar o aquecimento artificial em casos de frio intenso, quando a utilização das outras estratégias é insuficiente para se obter conforto térmico.

Há necessidade de maior conscientização da população, dos órgãos públicos e dos próprios arquitetos, que muitas vezes negligenciam os aspectos relacionados ao conforto ambiental e aos princípios bioclimáticos da arquitetura e do planejamento urbano. Priorizamse frequentemente outros critérios, em detrimento do bem estar e da saúde da população, e da economia energética (meio ambiente).

\section{Conclusão}

O AU-RMC se confirmou como exemplo representativo das relações socioespaciais urbanas contemporâneas e de suas contradições, devido à estrutura, às formas de ocupação e de uso do solo, à disparidade crescente entre os níveis sociais. As reais condições socioambientais frente à urbanização contrariam a imagem da cidade veiculada nacional e internacionalmente, o que conduz a uma visão crítica do planejamento urbano de Curitiba. Constatou-se que, interagindo com a dinâmica atmosférica, a urbanização produziu condições climáticas intraurbanas diferenciadas, que resultaram em distintas situações de conforto térmico, afetando os moradores de forma desigual, inquietação que motivou a elaboração desta pesquisa.

Assim, esse trabalho teve dois objetivos:

A análise da relação entre os graus de conforto térmico e desigualdades espaciais no AU-RMC; e. A elaboração de um breve panorama atualizado das pesquisas sobre o tema visando subsidiar pesquisas futuras. 
Ao contrário da maioria das cidades brasileiras, o desconforto térmico em Curitiba ocorre por frio/amplitude térmica. A gênese do clima urbano inclui o processo de formação da IC, sendo esperado que as temperaturas sejam mais baixas na periferia, o quê, de forma geral, se confirma. Na periferia a amplitude térmica tende a ser maior do que no centro urbano, pelos fatores já mencionados, fazendo coincidir, neste local, um duplo desconforto (por frio e amplitude térmica).

Devido ao efeito da IC, o desconforto térmico torna-se mais intenso na periferia urbana, ocupada pelas classes que dispõem de menos recursos, devido ao padrão de urbanização no país que se caracteriza pela periferização progressiva das classes menos favorecidas. As classes mais pobres tendem a se estabelecer em áreas cada vez mais periféricas e de maior vulnerabilidade socioambiental devido à pressão imobiliaria ou onde o ambiente é degradado, esquecido da administração municipal. Ou seja, coincidem as periferias geográfica e social $\mathrm{e}$ as áreas urbanas de maior desconforto térmico por frio, no AU-RMC, nas condições de inverno, período que se mostrou o mais crítico no clima local.

De modo geral, as classes menos favorecidas efetivamente habitam em lugares de maior rigor climático. Como agravante, também são estas pessoas que dispõem de menos recursos para se proteger do clima, pois têm menos acesso aos cuidados com a saúde, à alimentação adequada, à energia e a equipamentos condicionadores de água $\mathrm{e}$ ar, às vestimentas adequadas (segunda pele) e ao ambiente edificado (terceira pele), permanecendo à mercê do tempo.

Confirma-se, que o desenvolvimento da cidade de Curitiba gerou uma grande diferenciação urbana. No que diz respeito ao conforto térmico dos moradores, esta distribuição desigual induziu a uma intensificação da vulnerabilidade socioambiental da população em função das condições de vida.
Os resultados encontrados constituem importante subsídio para o planejamento da cidade e para o atendimento à população, pois foram definidas as áreas prioritárias de intervenção, visando à melhoria do conforto térmico de forma igualitária.

As pesquisas sobre clima urbano/ conforto térmico em Curitiba. Poucos estudos estabelecem a relação entre o clima urbano/conforto térmico e as desigualdades sociais em Curitiba. Considerando-se os canais de percepção do Sistema Clima Urbano (SCU) (Monteiro \& Mendonça, 2003), são raros os estudos sobre a vulnerabilidade socioambiental que contemplam o Conforto Térmico (Subsistema Termodinâmico), mas a versa sobre os outros dois canais: o Impacto Meteórico (Subsistema Hidrometeórico), e a Qualidade do Ar (Subsistema FísicoQuímico).

Foi possível traçar um breve panorama dos trabalhos sobre o conforto térmico urbano no AU-RMC, ainda que sem a vinculação com as desigualdades sociais. As pesquisas realizadas na última década indicam importantes avanços nos estudos do clima urbano e conforto térmico em Curitiba e seu aglomerado urbano, e evoluíram nas possibilidades de contribuir para o planejamento urbano do AU-RMC, adequando a cidade ao clima e visando a melhoria da qualidade de vida da população como um todo.

Observa-se lacunas nos estudos que relacionam a desigualdade social e a vulnerabilidade ao (des)conforto térmicoe também se evidencia a necessidade de evoluir nas investigações sobre as mudanças climáticas e sua interação com o clima urbano, devido às incertezas associadas ao tema.

Ao se confirmarem as tendências do clima, o desconforto térmico por frio em Curitiba e nas áreas mais inseridas na mancha urbana tende lentamente a diminuir com 
a elevação das temperaturas médias. $\mathrm{O}$ estudo realizado indica que a Ilha de Calor pode ser benéfica para Curitiba no inverno. Mas pouco se sabe sobre a conjugação dos efeitos da IC com as mudanças climáticas no verão no AU-RMC. Além disso, as alterações do clima local poderão trazer outras consequencias ainda não previstas.

Foram observadas algumas limitações no decorrer do estudo realizado:

O auxílio de pessoas leigas no assunto no monitoramento dos pontos. Embora se tenha realizado um treinamento prévio da leitura dos termo-higrômetros e do registro dos dados em planilhas, é possível que a falta de familiaridade com a escala de temperatura tenha resultado em imprecisões de leitura;

As interpolações espaciais não incluem pontos de medição nos centros secundários do aglomerado urbano;

O nível de representatividade dos pontos. Ainda que se tenha realizado um minucioso trabalho de sistematização das características naturais e construídas do AU-RMC e sua setorização em áreas relativamente homogêneas para a seleção dos pontos de monitoramento, a articulação das escalas apresenta dificuldades quanto ao seu nível de representatividade. Entre o grau de generalização da imagem de satélite e a microescala do monitoramento em campo, à medida que a escala se aproxima, amplia-se a complexidade do uso do solo devido aos processos inerentes à vida da cidade e há maior diversificação dos elementos do sítio. Apesar de todos os cuidados tomados, pequenos detalhes podem ter alterado a leitura das variáveis climáticas do ponto.

Observe-se, porém, que: ainda que o processo de seleção dos pontos seja sempre generalizante, seguiu-se a lógica da representatividade do clima local, apesar das limitações descritas, a análise dos dados coletados demonstrou certa coerência nos resultados.

Sugere-se para trabalhos futuros:

A revisão bibliográfica específica sobre os estudos que contemplem a relação entre clima urbano/conforto térmico e as desigualdades sociais;

A pesquisa bibliográfica sobre outras cidades do mundo onde o clima urbano/aquecimento global pode ser benéfico à população;

O aprofundamento do conhecimento das condições climáticas/de conforto térmico do AU-RMC, mediante um maior número de pontos de monitoramento, inclusive em centros urbanos secundários, analisando-se condições de inverno e verão e utilizando-se equipamentos do tipo data loggers;

A atualização do Ano Climático de Referência (TRY) para a década de 20082017, para embasar o planejamento urbano e o projeto bioclimático das edificações;

A investigação da amplitude térmica como critério de avaliação de conforto térmico;

O maior detalhamento da carta AU-RMC: condições de conforto térmico relacionadas às condições e qualidade de vida e elaboração de carta complementar para o desconforto por calor, visando ao atendimento da saúde pública nos episódios de temperaturas extremas;

O desenvolvimento do planejamento urbano do AU-RMC e de recomendações para a gestão urbana, a partir da verificação da hipótese como instrumento relevante para subsidiá-los.

\section{Agradecimentos}

Os autores agradecem o $\mathrm{CNPq}$ e a Capes pelo financiamento que viabilizou a realização da pesquisa. Agradecem também à MINEROPAR, Minerais do Paraná S/A, por 
ceder a Base Cartográfica utilizada na pesquisa, assim como ao INPE, Instituto Nacional de Pesquisas Espaciais por disponibilizar as imagens espaciais LANDSAT-5 TM - 220/78 e LANDSAT-7 ETM+, 220/078.

\section{Referencias}

Associação Brasileira de Normas Técnicas, ABNT (2005). Bioclimático brasileiro e diretrizes construtivas para habitações unifamiliares de interesse social (Informe NBR 15220-3: Desempenho térmico de edificações - Parte 3: Zoneamento). Rio de Janeiro: Autor.

Arnfield A. J. (2003). Two decades of urban climate research: a review of turbulence, exchanges of energy and water, and the urban heat island. International Journal of Climatology, 23, 1-26. https://doi. org/10.1002/joc.859

Broede P., Krueger E., Rossi F.A., \& Fiala D. (2012). Predicting urban outdoor thermal comfort by the Universal Thermal Climate Index UTCI a case study in Southern Brazil. International Journal of Biometeorology, 56(3), 471-480. https:// doi.org/10.1007/s00484-011-0452-3

Bruse M. \& Fleer H. (1998). Simulating surface-plant-air interacitions inside urban environments with a three dimensional numerical model.Environmental Modelling \& Software, 13(3-4), 373-384. https://doi. org/10.1016/s1364-8152(98)00042-5

Casagrande, A., Silva Junior, P., \& Mendonça, F. (2011). Mudanças climáticas e aquecimento global: controvérsias, incertezas e a divulgação científica. Revista Brasileira de Climatologia, 8. https://doi. org/10.5380/abclima.v8i0.25793

Centro de Previsão de Tempo e Estudos Climáticos, CPTEC (2006). Climanálise. Brasil: Autor.
Danni-Oliveira, I., Mendonca, F. A., Dumke, E. \& Schmitz, L. K. (2011). Restructuration urbaine et confort thermique: Scenarios de modelisation a Curitiba. Actes du: XXIV Colloque de l'Association Internationale de Climatologie. Rovereto. Ferrara: AICLIM. Univ. de Ferrara.

Danni-Oliveira, I.M. (2003). A cidade de Curitiba/PR e a poluição do ar. In: C.A.F. Monteiro \& F. Mendonça (Org.), Clima Urbano (pp. 155-174). São Paulo: Contexto.

Danni-Oliveira I. M. \& Mendonça F. (2000). Contribuição ao estudo do clima urbano de Curitiba, PR: considerações sobre suas características termo-higrométricas. Conference Proceedings: IV Simpósio Brasileiro de Climatologia Geográfica, SBCG. Rio de Janeiro.

Danni-Oliveira, I.M. (1999). Aspectos Climáticos de Curitiba-PR: uma contribuição para o ensino médio. Raega-O Espaço Geográfico em Análise, 3, 229-253. http:// dx.doi.org/10.5380/raega.v3i0.18233

Dumke, E. (2007). Clima urbano/conforto térmico e condições de vida na cidade - uma perspectiva a partir do Aglomerado Urbano da Região Metropolitana de Curitiba $(A U-R M C)$. (Tese de doutorado nãopublicada, Doutorado em Meio-Ambiente e Desenvolvimento). Universidade Federal do Paraná UFPR, Curitiba, Brasil.

Eliasson, I. (2000). The use of climate knowledge in urban planning. Landscape and Urban Planning, 48(1-2), 31-44. https:// doi.org/10.1016/s0169-2046(00)00034-7

Givoni, B. (1992). Comfort, climate analysis and building design guidelines. Energy and Buildings, 18 (1),11-23.

Instituto Brasileiro de Geografia e Estatística, IBGE. (2016). Atlas do Censo Demográfico. Brasil: Autor. http://www.ibge.gov.br 
Instituto Paranaense de Desenvolvimento Econômico e Social, IPARDES. (2010). Projeção da população total dos municípios do Paraná para o período 2016-2030 , alguns resultados. Recuperado de http:// www.ipardes.pr.gov.br/pdf/indices/projecao populacao_Parana_2016_2030_set.pdf

Instituto Paranaense de Desenvolvimento Econômico e Social, IPARDES. (2005). Indicadores intrametropolitanos 2000: diferenças socioespaciais na Região Metropolitana de Curitiba. Curitiba: IPARDES.

Johansson, E., Thorsson, S., Emmanuel, R., \& Krüger, E. (2014). Instruments and methods in outdoor thermal comfort studies. The need for standardization. Urban Climate, 10, 346-366. https://doi.org/10.1016/j.uclim.2013.12.002

Krüger, E. (2015). Urban heat island and indoor comfort effects in social housing dwellings. Landscape and Urban Planning, 134, 147-156. https://doi. org/10.1016/j.landurbplan.2014.10.017

Krüger, E., Minella, F.O; \& Matzarakis, A. (2013). Comparison of different methods of estimating the mean radiant temperature in outdoor thermal comfort studies. International Journal of Biometeorology, 58(8), 1.7271.737 https://doi.org/10.1007/s00484-0130777-1

Krüger, E. \& Rossi, F. A. (2011). Effect of personal and microclimatic variables on observed thermal sensation from a field study in southern Brazil. Building and Environment, 46(3), 690-697.

Krüger, E. \& Suga, M. (2009). Thermal and daylighting evaluation of the effect of varying aspect ratios in urban canyons in Curitiba, Brazil. Journal of Renewable and Sustainable Energy, 1(3), 033108. https://doi. org/10.1063/1.3153900
Krüger, E. \& Dumke, E. (2006). Compreendendo a ilha se calor de Curitiba: Comparação entre duas estações meteorológicas, uma urbana e outra rural na RMC. Anais do Seminário Internacional NUTAU, 1, 1-10.

Krüger, E. (2002). Experimentos simples na área de conforto e desempenho térmico. ABENGE-Revista de Ensino de Engenharia, 21 (1), 43-47.

Lamberts, R., Dutra, L., \& Pereira, F. (1997). Eficiência energética na arquitetura. São Paulo: PW Editores.

Leal, L., Biondi, D., \& Batista, A.C. (2014a). Efeitos da vegetação na variação térmica da cidade de Curitiba, PR. Floresta, 44 (3), 451- 464.

Leal, L., Biondi, D., \& Batista, AC. (2014b). Condições meteorológicas e diferenças térmicas diárias extremas no clima urbano da cidade de Curitiba. Scientia Plena, 10 (1), 1-11.

Lima, N. R., Pinheiro, G. M., \& Mendonça, F. (2012). Clima urbano no Brasil: análise e contribuição da metodologia de Carlos Augusto de Figueiredo Monteiro. Revista Geonorte, 2 (5), 626-638.

Martini, A., Biondi, D., Viezzer, J., \& da Silva D. A. (2015). O efeito microclimático do fragmento florestal existente no Parque Municipal do Barigui na cidade CuritibaPR. Ciência e Natura, 37, 125-131. https:// doi.org/10.5902/2179460x16227

Mendonça, F. (2010). Riscos e vulnerabilidades socioambientais urbanos: a contingência climática. Revista Mercator, 9 (1), 153.

Mendonça, F. \& Danni-Oliveira, I.M. (2007). Climatologia: noções básicas e climas do Brasil. São Paulo: Oficina de Texto. 
Mendonça, F. \& Dubreuil, V. (2005). Termografia de superfície e temperatura do ar na RMC (Região Metropolitana de Curitiba). Revista RA'E GA, 9, 25-35.

Mendonça, F. (2004a). (Org.). Cidade, desenvolvimento e meio ambiente: a abordagem interdisciplinar de problemáticas socioambientais urbanas de Curitiba e Região Metropolitana. Curitiba: Editora da UFPR.

Mendonça, F. (2004b). S.A.U. Sistema Ambiental Urbano: uma abordagem dos problemas socioambientais da cidade. In F. Mendonça, (Org.). Impactos Socioambientais Urbanos (pp. 185-207). Curitiba: Ed. da UFPR, 330

Mendonça,F.(1995).OClimaeo planejamento urbano de cidades de porte médio e pequeno: proposição metodológica para estudo e sua aplicação à cidade de Londrina/PR. (Tese de doutorado). Universidade de São Paulo, USP, São Paulo, Brasil.

Minella, F.O. \& Krüger, E. (2017). Proposition of a "vegetation fraction" index and its relationship with air temperature and thermal comfort changes during daytime in summer in Curitiba. Ambiente Construído, 17 (1), 353371

Minella, F.O., Krüger, E; \& Rasia F. (2011). Impact of urban geometry on outdoor thermal comfort and air quality from field measurements in Curitiba, Brazil. Building and Environment, 46 (3), 621-634.

Monteiro, C.A.F. \& Mendonça, F. (Org.) (2003). Clima Urbano. São Paulo: Contexto.

Monteiro, C.A.F. (1976). Teoria e clima urbano. São Paulo: IGEO/USP.

Oke, T.R. (2006). Initial guidance to obtain representative meteorological observations at urban sites. Genebra: WMO.
Oke, T.R. (1988). Street design and urban canopy layer climate. Energy and Buildings, 11, 103-113.

Pertschi, S., Lima, C. \& Danni-Oliveira, I.M. (2010). Considerações sobre a metodologia a respeito da alteração da temperatura do ar em ambiente urbano: estudo em São José dos Pinhais / PR. Revista brasileira de climatologia, 7, 37-46.

Rossi, F., Dumke, E; \& Krüger E. (2009). Atualização do ano climático de referência para Curitiba. Anais do X Encontro Nacional de Conforto do Ambiente Construído (ENCAC, 1-10).

Rossi, F.\& Krüger E. (2005). Análise da variação de temperaturas locais em função das características de ocupação do solo em Curitiba. Raega-O Espaço Geográfico em Análise, 10.

Santos, M. (1994). A urbanização brasileira. São Paulo: Hucitec

Schmitz, L. K. \& Mendonca, F. (2014). Simulação de cenários do clima urbano com emprego do ENVI-MET: cenários a partir do clima de Curitiba/Brasil. In C.A. Silva, E.S. Fialho \& E.T. Steinke, (Org.), Experimentos em Climatologia Geográfica (pp. 1-392). Dourados: UFGD.

Schmitz, L.K. \& Mendonca, F. (2011). Restruturação urbana e conforto térmico: cenários de modelização em Curitiba-PR após a copa de 2014. Revista brasileira de climatologia, 8, 61-81.

Silva, C. A. (2012). Análise topoclimática da temperatura e umidade relativa do ar sob influência da Massa de Ar Polar Atlântica (MPA). Revista Geonorte, 2(5), 150-161.

Sorre, M. (1984). A adaptação ao meio climático e biossocial-geografia psicológica. 
In J.F. Megale, (Org.). Max Sorre. São Paulo: Ática.

Stewart, I.D., Oke, T.R., \& Krayenhoff, E.S. (2014). Evaluation of the 'local climate zone scheme using temperature observations and model simulations. International Journal of Climatology, 34 (4), 1.062-1.080.
Young, A.F. \& Rocha J.V. (2006). Aplicação de índices relativos de vegetação e temperatura para análise das mudanças nos padrões de cobertura vegetal de Curitiba (PR). Floresta $e$ Ambiente, 13 (1), 34-43. 